\title{
Retail location competition under carbon penalty
}

\author{
Hande Dilek ${ }^{\mathrm{a}}$, Özgen Karaer ${ }^{\mathrm{b}, *}$, Emre Nadar ${ }^{\mathrm{c}}$ \\ a Academy Program Design Department, Aselsan Inc., Ankara 06370, Turkey \\ ${ }^{\mathrm{b}}$ Department of Industrial Engineering, Middle East Technical University, Ankara 06800, Turkey \\ ${ }^{\mathrm{c}}$ Department of Industrial Engineering, Bilkent University, 06800 Ankara, Turkey
}

\section{A R T I C L E I N F O}

\section{Article history:}

Received 31 August 2016

Accepted 28 October 2017

Available online 22 November 2017

\section{Keywords:}

OR in environment and climate change

Retail location

Competition

Carbon penalty

Game theory

\begin{abstract}
A B S T R A C T
We study the retail location problem in a competitive linear market in which two retailers simultaneously choose their locations. Both retailers procure identical products from a common supplier and each consumer purchases from the closest retailer. Each retailer incurs transportation costs for inventory replenishment from the warehouse and consumer travels to the store. We consider two carbon tax schemes imposed on retailers: for supply-chain-related transportation and for consumer-related transportation. Our analysis indicates that intense competition between retailers leads to a "minimal differentiation" equilibrium, which substantially increases the total system emissions. According to our numerical experiments with realistic parameter values, carbon tax on supply-chain-related transportation does not affect retail location decisions. Carbon tax on consumer transportation, however, may effectively induce the retailers to approach the middle of their respective markets, reducing the total system emissions. Our analysis also indicates that a low carbon price, relative to market profitability, only reduces the total system profit without any effect on emissions. Our findings suggest that the central policymaker avoid a uniform carbon price across different sources of emission and sectors with different characteristics.
\end{abstract}

(c) 2017 Elsevier B.V. All rights reserved.

\section{Introduction}

Increasing concentrations of greenhouse gases (GHGs) contribute to the change in global climate patterns and global warming. Carbon dioxide, methane, ozone, chlorofluorocarbons, nitrous oxide, and water vapor are the main GHGs existing in the atmosphere. Anthropogenic activities such as energy consumption, burning fossil fuels, deforestation, and transportation increase the amount of GHGs. Since the Industrial Revolution, the atmospheric concentration of carbon dioxide has increased by about $40 \%$, mostly due to the combustion of carbon-based fossil fuels, such as coal, oil, and gasoline (Intergovernmental Panel on Climate Change (Staff, 2014b), and Environmental Protection Agency (Staff, 2015)).

Transportation has been the second biggest source of GHG emissions in the U.S. and Europe in 2015, with shares of $27 \%$ and $23 \%$, respectively (Staff, 2016a; 2016b). In fact, in European Union, the transportation sector emissions did not follow the same gradual decline as in the other sectors, making the issue even more severe, considering the aggressive target of reaching $60 \%$ lower than the 1990 values by mid-century (Staff, 2017). In the U.S., about 61\% of the total transport emissions in 2015 was produced by vehicles of personal use whereas $23 \%$ is attributed to medium-and-heavy-

\footnotetext{
* Corresponding author.

E-mail addresses: hdilek@aselsan.com.tr (H. Dilek), okaraer@metu.edu.tr (Ö. Karaer), emre.nadar@bilkent.edu.tr (E. Nadar).
}

duty trucks (Staff, 2016a). Similarly, the total road transport is responsible for more than 70\% of Europe's transport emissions of 2014 (Staff, 2017).

Many countries, including Ireland, Australia, Chile, Sweden, Finland, Great Britain, and Canada, impose carbon taxes to reduce emissions. In British Columbia, for instance, "a carbon tax is usually defined as a tax based on GHG emissions generated from burning fuels. By reducing fuel consumption, increasing fuel efficiency, using cleaner fuels and adopting new technology, businesses and individuals can reduce the amount they pay in carbon tax, or even offset it altogether" (Staff, 2016c). With this progressive carbon tax policy enforced on individuals as well as businesses, the per-person fuel consumption in British Columbia dropped by $16 \%$ from 2008 to 2014, while it increased by $3 \%$ in the rest of Canada (Staff, 2014a).

Distances between a retailer and its suppliers greatly influence the total amount of carbon emissions in the transportation domain of a supply chain. But a retailer's location also influences the patronage to that retailer and the carbon emissions generated by consumers for their store visits. Hence the retail location with respect to both suppliers and consumers plays a key role in environmental performance of the market. Emissions from a retailer's own supply chain, including transportation, are generally classified as scope 1 emissions and tend to be the focus in carbon footprinting or any firm-focused regulation; see, for example, Toffel and Sice (2011). Alternatively, emissions that involve consumer 
travels and further down the supply chain for a retailer are generally classified as scope 3 emissions, and not a critical concern for retailers or policymakers.

In this paper, we study a competitive retail location problem under carbon penalty for transportation, including both upstream transportation to warehouse and downstream consumer visits to retailers. In a duopolistic market, by characterizing the changes in equilibrium locations, profits, and emissions, we investigate the effectiveness of different carbon tax schemes on transportation in the retailer's own supply chain versus on consumer travels. We also compare the duopolistic market performance with a benchmark: a monopolist retailer that determines the locations of its two stores in the market. In addition, we evaluate the "emission overage" by comparing our results with the environmentallyoptimal locations that minimize the total system emissions. In all settings, the retail stores procure identical products from a common supplier on the unit line in a full truck-load fashion, consumers are distributed uniformly on the unit line, each consumer travels to the closest store to purchase the product, and both retail stores sell their products at the same price.

The retailers take into account transportation costs due to both inventory replenishment and consumer travels in their profit calculations. Both types of transportation costs include fuel consumption and possible carbon emission costs. Supply-chain-related transportation poses a direct cost for the retailer. Consumerrelated transportation costs also influence retailers' profit performance. This may arise when carbon tax is enforced on consumers based on their fuel consumption, and retailers subsidize consumers through promotions and marketing campaigns (also known as "uniform delivered pricing"). This may also arise when retailers are liable for consumer-related transportation emissions (i.e., scope 3 emissions) and the related carbon tax.

Through an extensive numerical study, we find that without carbon tax enforced on transportation, retailers may choose locations that produce undesirable emission levels. Carbon tax on consumer-related transportation is substantially more effective in reducing total system emissions than carbon tax on supplierrelated transportation. In many cases, supplier-related transportation tax hurts retailer profits without any effect on emissions.

The competition intensity in the market is another critical factor in determining the effectiveness of the carbon policy. Accountability for both types of transportation is sufficient to align the monopolist retailer's location decisions with emission minimization. Even at very low carbon prices, the monopolist retailer easily achieves the minimum emission level possible in a fully functional market. However, in competitive markets, emissions tend to be substantially higher due to the "minimal differentiation" equilibrium. Competing retailers respond to carbon tax only when it is high enough, compared to the market profitability. A low carbon price in competitive markets only reduces the total system profit without any effect on emissions.

Based on our findings, we recommend that the central policymaker avoid a uniform carbon price across different sources of emission and sectors with different characteristics. By adjusted tax levels, emissions can be effectively reduced with minimum impact on business performance. In addition, carbon footprinting and accountability for the emissions directly involved with an organization's own operations (i.e., scope 1 emissions), as widely observed in practice, may fail to be effective or useful in a retail setting. As confirmed by the big share of transportation in overall emissions, and the substantial contribution of personal vehicles to transport emissions (Staff, 2016a), accountability for the consumer-contact and recovery of consumer-related carbon taxes from retailers will likely be an effective strategy towards reducing GHG emissions.

Our work is closely related with recent studies investigating the effect of carbon emission regulations on firms' operational deci- sions and the resulting emission levels. Several papers focus on the effect of carbon policy on the decisions involved with supply chain (e.g., Benjaafar, Li, and Daskin, 2013; Cachon, 2014; Caro, Corbett, Tan, and Zuidwijk, 2013; Hoen, Tan, Fransoo, and van Houtum, 2014, and Park, Cachon, Lai, \& Seshadri, 2015), facility location (e.g., Islegen, Plambeck, \& Taylor, 2016), co-products (e.g., Sunar \& Plambeck, 2016), and choice of green technology (e.g., Krass, Nedorezov, \& Ovchinnikov, 2013).

In this stream of literature, Cachon (2014) and Park et al. (2015) are the closest papers to ours; they both analyze the effect of carbon tax in the downstream part of a supply chain, from the inventory replenishment of retail stores to the consumer trips to stores. Although we share the main goal and several modeling assumptions with these two papers, we have significant differences in research questions, model details, and some insights. Cachon (2014) considers the operational trade-offs of a monopolist retail chain when she faces carbon tax, and examines the store location decisions alongside the size and number of stores to offer in an area. Unlike Cachon (2014), we focus on the effect of carbon tax in a competitive market. Park et al. (2015) consider both cases of monopoly and monopolistic competition, by endogenizing consumers' shopping frequency decisions. Unlike Park et al. (2015), we consider perfectly substitutable staple products, i.e., demand in each of our retailers is purely based on its (relative) location in the market via a Hotelling model. We find that carbon cost should be substantially high to be effective in the competitive market and taxing consumer travels is more effective than taxing retailer logistics operations, contradicting with the findings of Park et al. (2015).

Our research contributes to the carbon-regulated operations management literature a competitive location model in which retailers sell perfectly substitutable products and determine their locations in the presence of transportation costs due to both consumer travels and inventory replenishment from warehouse. We provide guidance to policymakers by characterizing the trade-off between the economic loss in the market versus the achieved reduction in emissions due to the carbon tax. We show that a possible retailer liability for consumer-related transportation is a crucial instrument in regulating retail locations in a competitive market. This finding calls into question the policymakers' traditional approach of monitoring and regulating scope 1 emissions only, which leaves scope 3 emissions unaccounted for despite their key role in achieving emission reduction.

Our work is also related with the competitive location literature, which is a mature research stream that can be dated back to Hotelling (1929). Most of this literature investigates the existence of, proposes methods to find, and/or characterizes the location equilibria. The papers in this stream can be roughly classified with respect to attributes such as location space, number of firms, existence of non-location decisions (e.g., price, quality, or capacity), pricing policy, timing of moves, demand (in)elasticity, and customer behavior. For a detailed survey and taxonomy of the competitive location literature, see Eiselt, Laporte, and Thisse (1993); Eiselt and Sandblom (2004); Graitson (1982); Plastria (2001); ReVelle and Eiselt (2005). Location space may be merely the unit interval (i.e., linear city) as we adopt in this paper (e.g., Dasci \& Laporte, 2005; D’Aspremont, Gabszewicz, \& Thisse, 1979; De Palma, Ginsburgh, \& Thisse, 1987; Granot, Granot, \& Raviv, 2010; Hotelling, 1929). The linear city model lends itself to the horizontal differentiation and product positioning problems. Location decisions may also take place in a multi-dimensional space (e.g., Diaz-Banez, Heredia, Pelegrin, Perez-Lantero, \& Ventura, 2011), in a network (e.g., Buechel \& Roehl, 2015; Dobson \& Karmarkar, 1987; Hakimi, 1983), or across a set of potential discrete locations (e.g., Aboolian, Berman, \& Krass, 2007; Godinho \& Dias, 2010; 2013; Küçükaydın, Aras, \& Altınel, 2011). Duopolistic competition, as we study in this 
paper, has received much attention in the literature (e.g., Balvers \& Szerb, 1996; Godinho \& Dias, 2013; Saiz, Hendrix, \& Pelegrin, 2011) whereas there are also papers that study the competition between three or more firms (e.g., Dasgupta \& Maskin, 1986; Eaton \& Lipsey, 1975; Rhim, Ho, \& Karmarkar, 2003). Price, quality, or capacity decisions may follow the location decisions in the problem setting (e.g., Diaz-Banez et al., 2011; Economides, 1986; Fernandez, Salhi, \& Boglarka, 2014; Meng, Huang, \& Cheu, 2009; Rhim et al., 2003; Saiz et al., 2011). Transportation-related costs may be incurred by the customer (i.e., mill pricing) (e.g., Dasci \& Laporte, 2005; De Palma et al., 1987), or may be incurred by the retailer in product price (i.e., delivered pricing) (e.g., Diaz-Banez et al., 2011; Fernandez et al., 2014). Firms may move sequentially (e.g., Granot et al., 2010), simultaneously (e.g., Godinho \& Dias, 2013), or in multiple simultaneous stages (e.g., Neven, 1985). Demand may be fixed, or may vary depending on price, distance, or an attraction attribute determined by the firms (e.g., Granot et al., 2010; Saiz et al., 2011). Customers may deterministically prefer the closest vendor, or may be heterogeneous in nature with probabilistic location choices (e.g., Balvers \& Szerb, 1996; Buechel \& Roehl, 2015).

We contribute to the competitive location literature by developing an environmental perspective on a static duopolistic linear city location problem with uniform delivered pricing. In this setting, we confirm the well-known "minimal differentiation" equilibrium with exogenous prices. Through extensive numerical studies with calibrated parameters, we evaluate the "emission overage" due to the competitive equilibrium, analyzing the market response in terms of both profits and emissions to possibly non-uniform carbon prices. This enables us to provide new insights into effective calibration of carbon prices in a well-known problem setting.

The remainder of the paper is organized as follows. We formulate our location problem in Section 2. We present our analysis of the duopoly and monopoly markets in Sections 3 and 4, respectively. We present and interpret our numerical results in Section 5. We discuss our insights and conclude the paper in Section 6. All proofs are contained in an online appendix.

\section{Problem formulation}

We study the location selection problem for two retailers $(i=A$ and $B$ ). Both retailers sell an identical product in a city represented by a line segment of unit length. A continuum of consumers is uniformly spread over the interval $[0,1]$. We denote by $a$ and $b$ the locations of retailers $A$ and $B$ on the unit line, respectively. Both retailers source the product from a common supplier (warehouse) located at $m \in[0,1]$ via trucks. Both retailers purchase the product from the warehouse at the same price $p_{m}$ and sell the product at the same price $p$. Without loss of generality we assume $p_{m}=0$. Total daily demand in the city is $\lambda$. Consumers travel straight lines to the nearest retailer to their home by passenger vehicles (car) to purchase one unit of the product. This is a standard assumption in the literature; see, for instance, Cachon (2014); Dobson and Karmarkar (1987); Küçükaydın et al. (2011). We denote by $\lambda_{i}(a, b)$ the total daily demand in retailer $i$. For example, if $a<b$, then the total daily demand in retailer $A$ is

$\lambda_{A}(a, b)=\lambda\left(\frac{a+b}{2}\right)$

and the total daily demand in retailer $B$ is

$\lambda_{B}(a, b)=\lambda\left(1-\frac{a+b}{2}\right)$.

Hence there are two types of transportation that take place for a product to be consumed: the retailer's inventory replenishment from the common supplier and the consumer's travel to the retailer. Both types of transportation (truck and car) lead to negative externalities in terms of carbon emissions. A carbon tax is enforced to curb transportation-related emissions in the system. Both types of transportation thus incur emission cost, in addition to the regular fuel and non-fuel costs.

Each retailer attracts the far located consumers by compensating their transportation costs, in order to sell her products. Transportation cost per unit consumption is proportional to the distance traveled by the consumer; the farther the consumers travel to visit the retailer, the more emission tax and transportation cost they pay. Each retailer thus wants to be close to the warehouse to reduce her replenishment costs, but also close to her consumer base to reduce her compensation costs.

We adopt the model in Cachon (2014) in quantifying the retailers' revenue and cost trade-offs: We define $c_{c}$ as the transportation cost per unit of distance traveled by consumer per unit of product purchased, and $c_{t}$ as the transportation cost per unit of distance traveled by truck per unit of product delivered. (The subscripts ' $c$ ' and ' $t$ ' refer to 'cars' and 'trucks,' respectively.) Transportation costs are influenced by the fuel efficiency of the vehicles used, the weight of the loads they carry, and the distance they travel. Thus we formulate $c_{c}$ and $c_{t}$ in terms of the non-fuel variable cost to transport the vehicle $j$ per unit of distance $\left(v_{j}\right)$, the amount of fuel used to transport the vehicle $j$ per unit of distance $\left(f_{j}\right)$, the per unit cost of fuel $\left(p_{j}\right)$, the amount of carbon emission released by consumption of one unit of fuel $\left(e_{j}\right)$, the price of carbon or cost of emissions per unit released $\left(p_{e, j}\right)$, and the load carried by vehicle $j\left(q_{j}\right)$, for $j \in\{c, t\}$. When the government increases the emission taxes, $p_{e, j}$ increases. Note that high values of $p_{e, j}$ motivate the retailers to reduce their carbon emissions. Thus:

$c_{j}=\frac{v_{j}+f_{j}\left(p_{j}+e_{j} p_{e, j}\right)}{q_{j}}$ for $j \in\{c, t\}$.

The cost $c_{j}$ consists of the fuel cost $\frac{f_{j}\left(p_{j}+e_{j} p_{e, j}\right)}{q_{j}}$ and the non-fuel cost $\frac{v_{j}}{q_{j}}$. The fuel cost includes the price of carbon $\frac{f_{j} e_{j} p_{e, j}}{q_{j}}$ where $\frac{f_{j} e_{j}}{q_{j}}$ is the amount of carbon emissions. Note that when $v_{c}=p_{c}=$ 0 , our cost formulation would also reflect a setting where the retailers do not compensate the consumers, but instead pay a carbon tax contingent on the travel of their customers.

Trucks can carry significantly larger quantities than cars. As a result, the economies of scale effect between the truck-load and the passenger-car-load often dominates the transportation cost coefficients. Thus it is not restrictive to assume $c_{c}>c_{t}$. In their numerical experiments Cachon (2014); Park et al. (2015) assume $c_{c} / c_{t}=235$. In this study we restrict our analysis to the case with $p>c_{c}>2 c_{t}$.

Assumption 1. $p>c_{c}>2 c_{t}$.

Last, we define $d_{i c}(a, b)$ as the average round-trip distance a consumer travels to retailer $i$ and $d_{i t}(a, b)$ as the length of truck's route from retailer $i$ to the warehouse. For a given warehouse location $m$, the daily profit of retailer $i, \pi_{i}(a, b)$, can be written as

$$
\begin{array}{r}
\pi_{i}(a, b)=\left[p-c_{c} d_{i c}(a, b)-c_{t} d_{i t}(a, b)\right] \lambda_{i}(a, b) \\
\text { for } a \in[0,1], b \in[0,1], i \in\{A, B\} .
\end{array}
$$

The retailers' demand and cost structures depend on their relative locations, with respect to each other and the warehouse. We characterize eight distinct location combinations in Table 1; we will formulate the retailers' profit functions in each of these cases. We define $\pi_{A}^{(j)}(a, b)$ and $\pi_{B}^{(j)}(a, b)$ as the profits of retailers $A$ and $B$ in case $(j)$, respectively. We below show our calculation steps to derive $\pi_{A}^{(1)}(a, b)$ and $\pi_{B}^{(1)}(a, b)$ in case (1). We relegated our calculation steps to derive $\pi_{A}^{(j)}(a, b)$ and $\pi_{B}^{(j)}(a, b)$ in cases (2)-(8) to the online appendix. 
Table 1

Eight distinct location cases in our problem formulation.

\begin{tabular}{ll}
\hline Case (1) & $0 \leq a<b \leq m \leq 1$ \\
Case (2) & $0 \leq a=b \leq m \leq 1$ \\
Case (3) & $0 \leq b<a \leq m \leq 1$ \\
Case (4) & $0 \leq b \leq m<a \leq 1$ \\
Case (5) & $0 \leq a<m<b \leq 1$ \\
Case (6) & $0 \leq m \leq a<b \leq 1$ \\
Case (7) & $0 \leq m<a=b \leq 1$ \\
Case (8) & $0 \leq m<b<a \leq 1$ \\
\hline
\end{tabular}

Suppose that $0 \leq a<b \leq m \leq 1$ (case 1 ). The average round-trip distance traveled by a consumer to retailer $A$ is

$d_{A c}(a, b)=\frac{2\left[\int_{0}^{a}(a-t) d t+\int_{a}^{\frac{a+b}{2}}(t-a) d t\right]}{\frac{a+b}{2}}=\frac{5 a^{2}-2 a b+b^{2}}{2 a+2 b}$

and the average round-trip distance traveled by a consumer to retailer $B$ is

$$
\begin{aligned}
d_{B C}(a, b) & =\frac{2\left[\int_{b}^{1}(t-b) d t+\int_{\frac{a+b}{2}}^{b}(b-t) d t\right]}{1-\frac{a+b}{2}} \\
& =\frac{a^{2}-2 a b+5 b^{2}-8 b+4}{4-2 a-2 b} .
\end{aligned}
$$

The round-trip distance traveled by a truck from the warehouse to retailers $A$ and $B$ are $d_{A t}(a, b)=2(m-a)$ and $d_{B t}(a, b)=2(m-b)$, respectively. Hence the daily profit of retailer $A$ can be written as

$$
\begin{aligned}
\pi_{A}^{(1)}(a, b)= & \frac{\lambda p(a+b)}{2}-\frac{\lambda c_{c}\left(5 a^{2}-2 a b+b^{2}\right)}{4} \\
& -\lambda c_{t}(a+b)(m-a)
\end{aligned}
$$

and the daily profit of retailer $B$ can be written as

$$
\begin{aligned}
\pi_{B}^{(1)}(a, b)= & \frac{\lambda p(2-a-b)}{2}-\frac{\lambda c_{c}\left(a^{2}-2 a b+5 b^{2}-8 b+4\right)}{4} \\
& -\lambda c_{t}(2-a-b)(m-b) .
\end{aligned}
$$

Table 2 exhibits the profit functions in each of our cases. In the remainder of the paper we use the profit functions in Table 2 to analyze the retail location problem. In Section 3, we consider a competitive market in which the two retailers want to choose their locations on the unit line to maximize their individual profits. In Section 4, we consider a monopolist retail chain who wants to locate two of its stores, $A$ and $B$ respectively, on the unit line to maximize its total profit.

\section{Competing retailers}

In this section we consider a competitive market in which the two retailers simultaneously choose their locations to maximize

Table 2

Profit functions in eight distinct location cases.

\begin{tabular}{ll}
$\pi_{A}^{(1)}(a, b)$ & $\frac{2 \lambda p(a+b)-\lambda c_{c}\left(5 a^{2}-2 a b+b^{2}\right)}{4}-\lambda c_{t}(a+b)(m-a)$ \\
$\pi_{B}^{(1)}(a, b)$ & $\frac{2 \lambda p(2-a-b)-\lambda c_{c}\left(a^{2}-2 a b+5 b^{2}-8 b+4\right)}{4}-\lambda c_{t}(2-a-b)(m-b)$ \\
$\pi_{A}^{(2)}(a, b)$ & $\frac{\lambda p-\lambda c_{c}\left(1-2 a+2 a^{2}\right)}{2}-\lambda c_{t}(m-a)$ \\
$\pi_{B}^{(2)}(a, b)$ & $\frac{\lambda p-\lambda c_{c}\left(1-2 a+2 a^{2}\right)}{2}-\lambda c_{t}(m-a)$ \\
$\pi_{A}^{(3)}(a, b)$ & $\frac{2 \lambda p(2-a-b)-\lambda c_{c}\left(b^{2}-2 a b+5 a^{2}-8 a+4\right)}{4}-\lambda c_{t}(2-a-b)(m-a)$ \\
$\pi_{B}^{(3)}(a, b)$ & $\frac{2 \lambda p(a+b)-\lambda c_{c}\left(5 b^{2}-2 a b+a^{2}\right)}{4}-\lambda c_{t}(a+b)(m-b)$ \\
$\pi_{A}^{(4)}(a, b)$ & $\frac{2 \lambda p(2-a-b)-\lambda c_{c}\left(b^{2}-2 a b+5 a^{2}-8 a+4\right)}{4}-\lambda c_{t}(2-a-b)(a-m)$ \\
$\pi_{B}^{(4)}(a, b)$ & $\frac{2 \lambda p(a+b)-\lambda c_{c}\left(5 b^{2}-2 a b+a^{2}\right)}{4}-\lambda c_{t}(a+b)(m-b)$ \\
$\pi_{A}^{(5)}(a, b)$ & $\frac{2 \lambda p(a+b)-\lambda c_{c}\left(5 a^{2}-2 a b+b^{2}\right)}{4}-\lambda c_{t}(a+b)(m-a)$ \\
$\pi_{B}^{(5)}(a, b)$ & $\frac{2 \lambda p(2-a-b)-\lambda c_{c}\left(a^{2}-2 a b+5 b^{2}-8 b+4\right)}{4}-\lambda c_{t}(2-a-b)(b-m)$ \\
$\pi_{A}^{(6)}(a, b)$ & $\frac{2 \lambda p(a+b)-\lambda c_{c}\left(5 a^{2}-2 a b+b^{2}\right)}{4}-\lambda c_{t}(a+b)(a-m)$ \\
$\pi_{B}^{(6)}(a, b)$ & $\frac{2 \lambda p(2-a-b)-\lambda c_{c}\left(a^{2}-2 a b+5 b^{2}-8 b+4\right)}{4}-\lambda c_{t}(2-a-b)(b-m)$ \\
$\pi_{A}^{(7)}(a, b)$ & $\frac{\lambda p-\lambda c_{c}\left(1-2 a+2 a^{2}\right)}{2}-\lambda c_{t}(a-m)$ \\
$\pi_{B}^{(7)}(a, b)$ & $\frac{\lambda p-\lambda c_{c}\left(1-2 a+2 a^{2}\right)}{2}-\lambda c_{t}(a-m)$ \\
$\pi_{A}^{(8)}(a, b)$ & $\frac{2 \lambda p(2-a-b)-\lambda c_{c}\left(b^{2}-2 a b+5 a^{2}-8 a+4\right)}{4}-\lambda c_{t}(2-a-b)(a-m)$ \\
$\pi_{B}^{(8)}(a, b)$ & $\frac{2 \lambda p(a+b)-\lambda c_{c}\left(5 b^{2}-2 a b+a^{2}\right)}{4}-\lambda c_{t}(a+b)(b-m)$ \\
\hline
\end{tabular}

their individual profits. We first analytically characterize the best response functions of the retailers. We then establish the Nash equilibrium locations when the warehouse is in the middle of the unit line, based on the contraction mapping of the best responses. Section 5 provides further (numerical) results and insights on the competitive market. ${ }^{1}$

Recall that the warehouse is located at point $m \in[0,1]$. Below we characterize the best response function of retailer $A$ in each of the following two scenarios: (i) when retailer $B$ is located at point $b \leq m$ and (ii) when it is located at point $b>m$. We assume that the in-store price $p$ is sufficiently large so that it is always profitable for each retailer to stay in the market.

First suppose that $b \leq m$. Retailer $A$ can locate herself on the unit line so that case (1), (2), (3), or (4) in Table 1 holds. Thus the profit of retailer $A$ takes one of those forms in cases (1)-(4) of Table 2 . We characterize retailer $A$ 's optimal profit and location in each of cases (1)-(4), and identify its optimal location when $b \leq m$ as the one that maximizes her profit across all these cases.

- Suppose that $0 \leq a<b \leq m \leq 1$ (case 1). Under Assumption 1, we are able to prove that retailer $A$ 's profit function $\pi_{A}^{(1)}(a, b)$ is concave in $a$. The unconstrained maximizer of $\pi_{A}^{(1)}(a, b)$ is $a_{1}^{o}=\frac{p+c_{c} b+2 c_{t}(b-m)}{5 c_{c}-4 c_{t}}$. However, as we assume $0 \leq a<b$, retailer $A$ 's optimal location and profit in case (1) are given by

$$
\begin{aligned}
& \left(a_{1}^{*}, \pi_{A}^{(1)}\left(a_{1}^{*}, b\right)\right) \\
& \quad= \begin{cases}\left(a_{1}^{o}, \pi_{A}^{(1)}\left(a_{1}^{o}, b\right)\right) & \text { if } 0 \leq a_{1}^{o}<b \text { (C.1.a), } \\
\left(0, \pi_{A}^{(1)}(0, b)\right) & \text { if } a_{1}^{o}<0 \text { (C.1.b), and } \\
\emptyset & \text { otherwise, i.e., } a_{1}^{o} \geq b \text { (C.1.c). }\end{cases}
\end{aligned}
$$

But condition (C.1.b) is infeasible under Assumption 1. We detail conditions (C.1.a) and (C.1.c) in the online appendix.

- Suppose that $0 \leq a=b \leq m \leq 1$ (case 2). Thus:

$$
\pi_{A}^{(2)}(b, b)=\lambda\left(\frac{p-c_{c}\left(1-2 b+2 b^{2}\right)}{2}-c_{t}(m-b)\right) \text {. }
$$

- Suppose that $0 \leq b<a \leq m \leq 1$ (case 3). Again, under Assumption 1, we are able to prove that retailer A's profit function $\pi_{A}^{(3)}(a, b)$ is concave in $a$. The unconstrained maximizer of $\pi_{A}^{(3)}(a, b)$ is $a_{3}^{o}=\frac{-p+c_{c}(4+b)+2 c_{t}(2+m-b)}{5 c_{c}+4 c_{t}}$. However, as we assume $b<a \leq m$, retailer $A$ 's optimal location and profit in case (3) are given by

$$
\begin{aligned}
& \left(a_{3}^{*}, \pi_{A}^{(3)}\left(a_{3}^{*}, b\right)\right) \\
& \quad= \begin{cases}\left(a_{3}^{o}, \pi_{A}^{(3)}\left(a_{3}^{o}, b\right)\right) & \text { if } b<a_{3}^{o} \leq m \text { (C.3.a), } \\
\left(m, \pi_{A}^{(3)}(m, b)\right) & \text { if } a_{3}^{o}>m \text { (C.3.b), and } \\
\varnothing & \text { otherwise, i.e., } a_{3}^{o} \leq b \text { (C.3.c). }\end{cases}
\end{aligned}
$$

We detail conditions (C.3.a), (C.3.b), and (C.3.c) in the online appendix.

- Suppose that $0 \leq b \leq m<a \leq 1$ (case 4). Again, under Assumption 1, we are able to prove that retailer $A$ 's profit function $\pi_{A}^{(4)}(a, b)$ is concave in $a$. The unconstrained maximizer of $\pi_{A}^{(4)}(a, b)$ is $a_{4}^{o}=\frac{-p+c_{c}(4+b)-2 c_{t}(2+m-b)}{5 c_{c}-4 c_{t}}$. However, as we assume $m<a \leq 1$, retailer $A$ 's optimal location and profit in case (4) are given by

$$
\begin{aligned}
& \left(a_{4}^{*}, \pi_{A}^{(4)}\left(a_{4}^{*}, b\right)\right) \\
& \quad= \begin{cases}\left(a_{4}^{o}, \pi_{A}^{(4)}\left(a_{4}^{o}, b\right)\right) & \text { if } m<a_{4}^{o} \leq 1 \text { (C.4.a), } \\
\left(1, \pi_{A}^{(4)}(1, b)\right) & \text { if } a_{4}^{o}>1 \text { (C.4.b), and } \\
\emptyset & \text { otherwise, i.e., } a_{4}^{o} \leq m \text { (C.4.c). }\end{cases}
\end{aligned}
$$

${ }^{1}$ We also considered the competitive location problem in a three-retailer environment. But, in this setting, no pure strategy equilibrium exists on our test bed in Section 5. We thus omitted analysis of this setting from our study. 
Table 3

Best response of retailer $A$ when $b \leq m$.

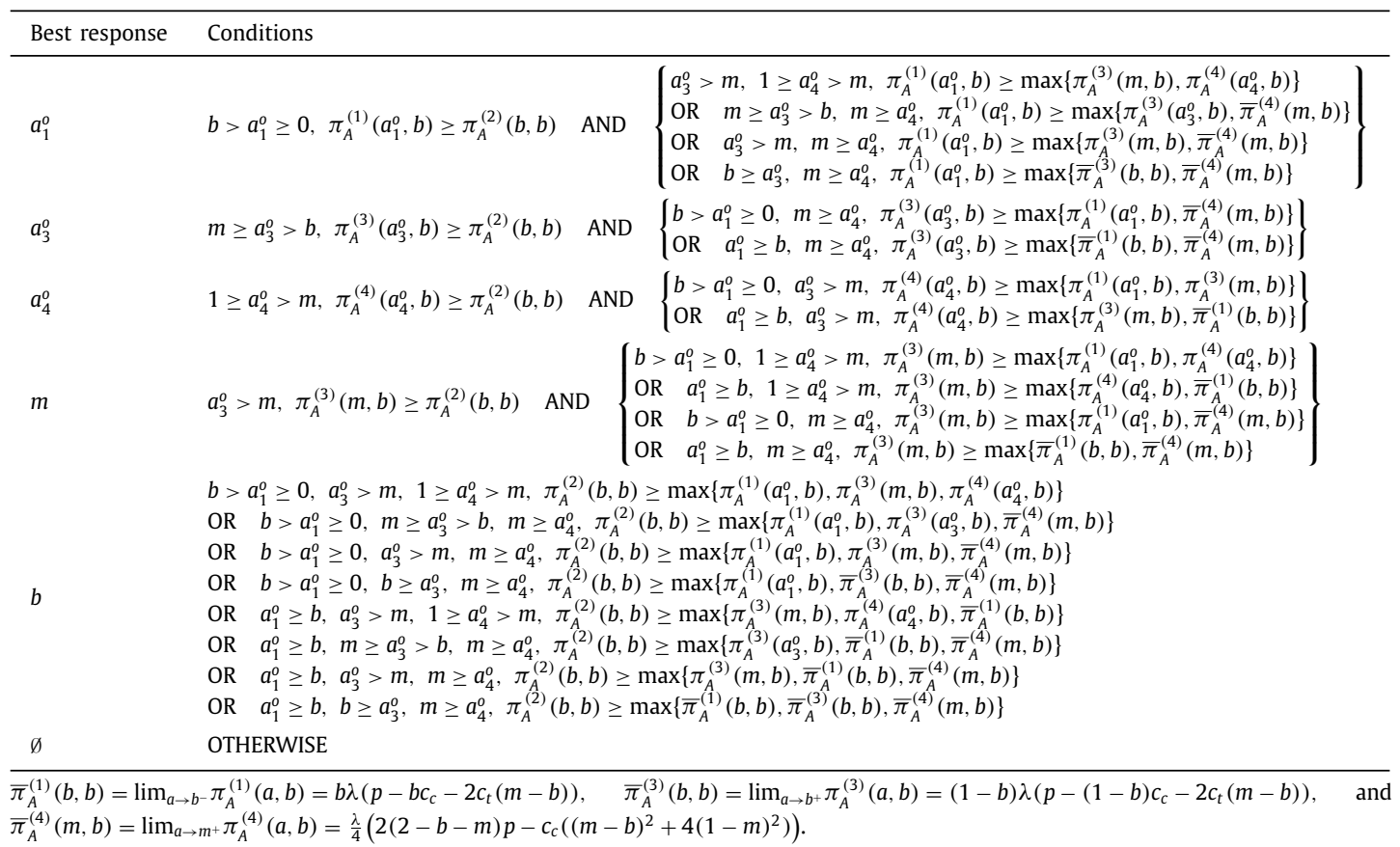

But condition (C.4.b) is infeasible under Assumption 1. We detail conditions (C.4.a) and (C.4.c) in the online appendix.

Thus, given $b \leq m$, we find the optimal location of retailer $A$ (the maximizer of retailer $A$ 's profit) in each of cases (1)-(4). The best response of retailer $A$ should give the maximum profit to retailer $A$ among cases (1)-(4). If the optimal location of retailer $A$ is $\emptyset$ in any case since the feasible region of the case is not compact, we take into consideration the profit at the end-point that cannot be achieved in the feasible region of that case, in our calculation of the maximum profit among cases (1)-(4). However, if the maximum profit occurs at an end-point that cannot be achieved in the feasible region of any case, then retailer $A$ 's best response becomes $\emptyset$. Proposition 1 characterizes the best response of retailer $A$ to retailer B's location choice when $b \leq m$.

Proposition 1. Suppose that Assumption 1 holds and retailer $B$ is located at $b \leq m$. Retailer A's best response location to $b$ is given in Table 3.

Now suppose that $b>m$. Retailer $A$ can locate herself on the unit line so that case (5), (6), (7), or (8) in Table 1 holds. Thus the profit of retailer $A$ takes one of those forms in cases (5)-(8) of Table 2 . We characterize retailer $A$ 's optimal profit and location in each of cases (5)-(8), and identify its optimal location when $b>m$ as the one that maximizes her profit across all these cases.

- Suppose that $0 \leq a<m<b \leq 1$ (case 5). Under Assumption 1, we are able to prove that retailer $A$ 's profit function $\pi_{A}^{(5)}(a, b)$ is concave in $a$. The unconstrained maximizer of $\pi_{A}^{(5)}(a, b)$ is $a_{5}^{0}=\frac{p+c_{c} b+2 c_{t}(b-m)}{5 c_{c}-4 c_{t}}$. However, as we assume $0 \leq a<m$, retailer $A$ 's optimal location and profit in case (5) are given by

$$
\begin{aligned}
& \left(a_{5}^{*}, \pi_{A}^{(5)}\left(a_{5}^{*}, b\right)\right) \\
& \quad= \begin{cases}\left(a_{5}^{o}, \pi_{A}^{(5)}\left(a_{5}^{o}, b\right)\right) & \text { if } 0 \leq a_{5}^{o}<m \text { (C.5.a), } \\
\left(0, \pi_{A}^{(5)}(0, b)\right) & \text { if } a_{5}^{o}<0 \text { (C.5.b), and } \\
\emptyset & \text { otherwise, i.e., } a_{5}^{o} \geq m \text { (C.5.c). }\end{cases}
\end{aligned}
$$

But condition (C.5.b) is infeasible under Assumption 1. We detail conditions (C.5.a) and (C.5.c) in the online appendix.
- Suppose that $0 \leq m \leq a<b \leq 1$ (case 6). Again, under Assumption 1, we are able to prove that retailer A's profit function $\pi_{A}^{(6)}(a, b)$ is concave in $a$. The unconstrained maximizer of $\pi_{A}^{(6)}(a, b)$ is $a_{6}^{o}=\frac{p+c_{c} b+2 c_{t}(m-b)}{5 c_{c}+4 c_{t}}$. However, as we assume $m \leq a<b$, retailer $A$ 's optimal location and profit in case (6) are given by

$$
\begin{aligned}
& \left(a_{6}^{*}, \pi_{A}^{(6)}\left(a_{6}^{*}, b\right)\right) \\
& \quad= \begin{cases}\left(a_{6}^{o}, \pi_{A}^{(6)}\left(a_{6}^{o}, b\right)\right) & \text { if } m \leq a_{6}^{o}<b \text { (C.6.a), } \\
\left(m, \pi_{A}^{(6)}(m, b)\right) & \text { if } a_{6}^{o}<m \text { (C.6.b), and } \\
\emptyset & \text { otherwise, i.e., } a_{6}^{o} \geq b \text { (C.6.c). }\end{cases}
\end{aligned}
$$

We detail conditions (C.6.a), (C.6.b), and (C.6.c) in the online appendix.

- Suppose that $0 \leq m<a=b \leq 1$ (case 7). Note that $a=b$ in this case. Thus:

$$
\pi_{A}^{(7)}(b, b)=\lambda\left(\frac{p-c_{c}\left(1-2 b+2 b^{2}\right)}{2}-c_{t}(b-m)\right) \text {. }
$$

- Suppose that $0 \leq m<b<a \leq 1$ (case 8). Again, under Assumption 1, we are able to prove that retailer $A$ 's profit function $\pi_{A}^{(8)}(a, b)$ is concave in $a$. The unconstrained maximizer of $\pi_{A}^{(8)}(a, b)$ is $a_{8}^{0}=\frac{-p+c_{c}(4+b)+2 c_{t}(b-m-2)}{5 c_{c}-4 c_{t}}$. However, as we assume $b<a \leq 1$, retailer $A$ 's optimal location and profit in case (8) are given by

$$
\begin{aligned}
& \left(a_{8}^{*}, \pi_{A}^{(8)}\left(a_{8}^{*}, b\right)\right) \\
& \quad= \begin{cases}\left(a_{8}^{o}, \pi_{A}^{(8)}\left(a_{8}^{o}, b\right)\right) & \text { if } b<a_{8}^{o} \leq 1 \text { (C.8.a), } \\
\left(1, \pi_{A}^{(8)}(1, b)\right) & \text { if } a_{8}^{o}>1 \text { (C.8.b), and } \\
\emptyset & \text { otherwise, i.e., } a_{8}^{o} \leq b \text { (C.8.c). }\end{cases}
\end{aligned}
$$

But condition (C.8.b) is infeasible under Assumption 1. We detail conditions (C.8.a) and (C.8.c) in the online appendix. 
Table 4

Best response of retailer $A$ when $b>m$.

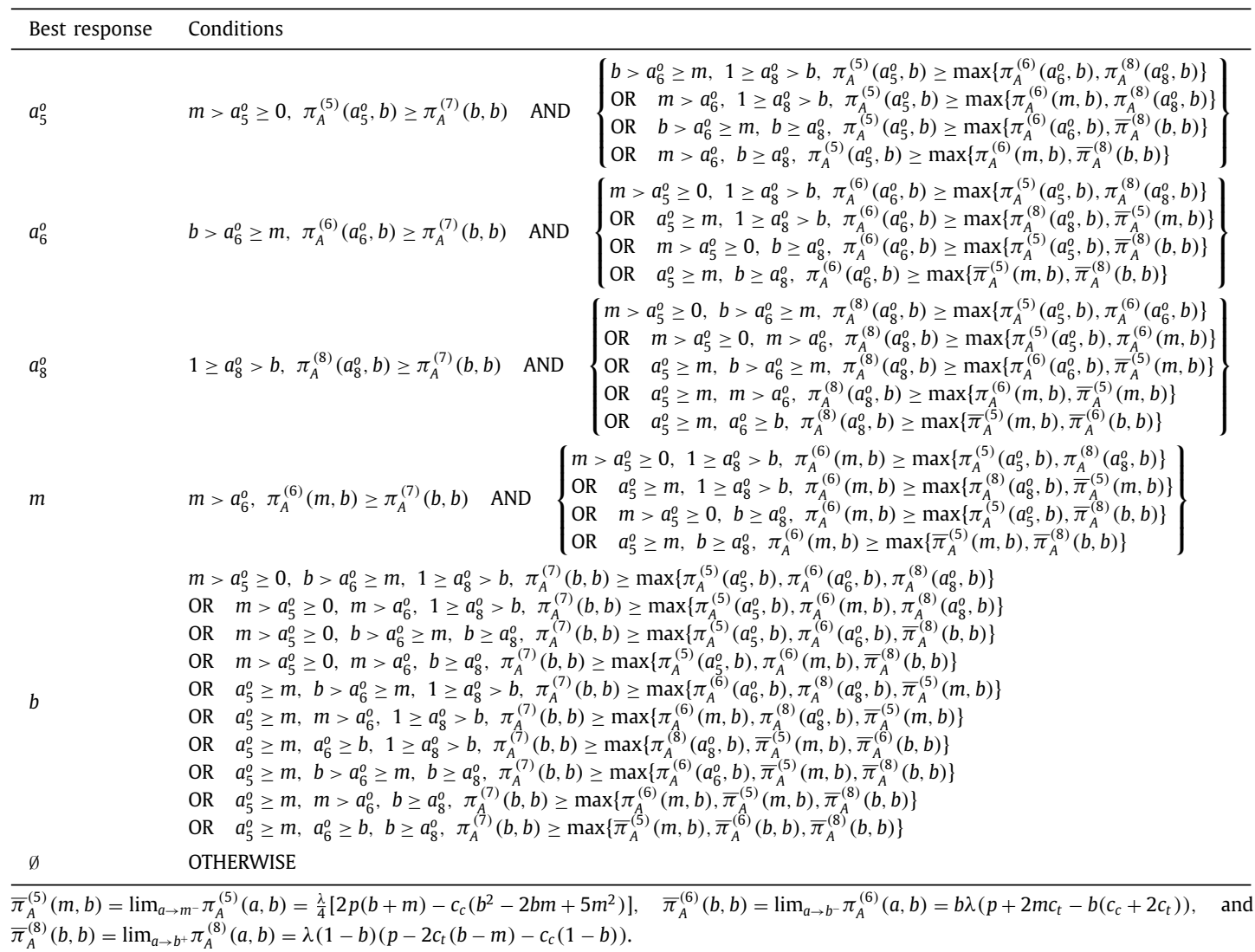

Proposition 2 characterizes the best response of retailer $A$ to retailer $B$ 's location choice when $b>m$.

Proposition 2. Suppose that Assumption 1 holds and retailer $B$ is located at $b>m$. Retailer A's best response location to $b$ is given in Table 4.

Proposition 3 establishes the Nash equilibrium locations when the warehouse is exactly in the middle of the unit line, i.e., $m=$ 0.5 .

Proposition 3. Suppose that Assumption 1 holds and $m=0.5$.

(a) (Symmetric equilibrium.) If $p \geq 2 c_{c}-2 c_{t}$, then the pair of locations $(0.5,0.5)$ is a Nash equilibrium solution.

(b) (Asymmetric equilibrium.) If $p<2 c_{c}-2 c_{t}$, then the pair of locations $\left(\frac{c_{c}+c_{t}+p}{6 c_{c}-2 c_{t}}, \frac{5 c_{c}-3 c_{t}-p}{6 c_{c}-2 c_{t}}\right)$ is a Nash equilibrium solution.

When the price is sufficiently high, the market incentives dominate the transportation costs in retailers' location decisions. As a result, each retailer has less incentive to reduce her transportation costs by staying close to the warehouse and her consumer base, but more incentive to capture more demand under competition. The retailers thus get closer to each other in order to serve a larger demand. Proposition 3(a) shows that they eventually end up at the same location in equilibrium so that the total demand is split equally between the two retailers. When the price is sufficiently low, each retailer has more incentive to reduce her transportation costs. Proposition 3(b) states that the retailers choose asymmetric locations on different sides of the warehouse in equilibrium so that each retailer is very close to both the warehouse and her consumer base.

\section{Monopolist retail chain}

In this section, we consider a single retail chain who wants to locate two of her own stores on the unit line so as to maximize her total profit. The optimization problem of such a retail chain is given by

$$
\begin{array}{ll}
\underset{a, b}{\operatorname{maximize}} & \pi_{A}(a, b)+\pi_{B}(a, b) \\
\text { subject to } & 0 \leq a, b \leq 1 .
\end{array}
$$

We again assume that the in-store price $p$ is sufficiently large so that it is always optimal to stay in the market.

Table 5 exhibits the total profit function of the retail chain that arises in each of the eight cases described in Section 2: $\pi_{T}^{(i)}(a, b)$ is the total profit when the stores are located at points $a$ and $b$ such that case (i) in Table 1 holds, i.e., $\pi_{T}^{(i)}(a, b)=\pi_{A}^{(i)}(a, b)+\pi_{B}^{(i)}(a, b)$. The total profit function, in Table 5 , is a piecewise function in both $a$ and $b$. Lemma 1(a) shows that the total profit function is continuous in both $a$ and $b$. Lemma 1(b) shows that the total profit function in each case (i.e., each piece) is jointly concave in $a$ and $b$.

Table 5

Total profit functions for the monopolist retail chain.

$$
\begin{array}{ll}
\pi_{T}^{(1)}(a, b) & \lambda\left[p+c_{c}\left(2 b+a b-1-\frac{3 a^{2}+3 b^{2}}{2}\right)+c_{t}\left(2 b-2 m+a^{2}-b^{2}\right)\right] \\
\pi_{T}^{(2)}(a, b) & \lambda\left[p-c_{c}\left(a^{2}-a+b^{2}-b+1\right)-c_{t}(2 m-a-b)\right] \\
\pi_{T}^{(3)}(a, b) & \lambda\left[p+c_{c}\left(2 a+a b-1-\frac{3 a^{2}+3 b^{2}}{2}\right)+c_{t}\left(2 a-2 m+b^{2}-a^{2}\right)\right] \\
\pi_{T}^{(4)}(a, b) & \lambda\left[p+c_{c}\left(a b+2 a-1-\frac{3 a^{2}+3 b^{2}}{2}\right)-c_{t}\left(2 m(a+b-1)-(a+b)^{2}+2 a\right)\right] \\
\pi_{T}^{(5)}(a, b) & \lambda\left[p+c_{c}\left(a b+2 b-1-\frac{3 a^{2}+3 b^{2}}{2}\right)-c_{t}\left(2 m(a+b-1)-(a+b)^{2}+2 b\right)\right] \\
\pi_{T}^{(6)}(a, b) & \lambda\left[p+c_{c}\left(2 b+a b-1-\frac{3 a^{2}+3 b^{2}}{2}\right)+c_{t}\left(2 m-2 b+b^{2}-a^{2}\right)\right] \\
\pi_{T}^{(7)}(a, b) & \lambda\left[p-c_{c}\left(a^{2}-a+b^{2}-b+1\right)+c_{t}(2 m-a-b)\right] \\
\pi_{T}^{(8)}(a, b) & \lambda\left[p+c_{c}\left(2 a+a b-1-\frac{3 a^{2}+3 b^{2}}{2}\right)+c_{t}\left(2 m-2 a+a^{2}-b^{2}\right)\right] \\
\hline
\end{array}
$$


Lemma 1. Suppose that Assumption 1 holds.

(a) For a given $b$ (or $a$ ), the total profit function of a retail chain with stores located at points $a$ and $b$ is continuous in $a$ (or $b$ ).

(b) The total profit function $\pi_{T}^{(i)}(a, b)$ is jointly concave in $a$ and $b$ in its respective feasible region, $\forall i$.

Because the total profit functions are continuous and each piece is jointly concave in its feasible region, we are able to develop a solution algorithm for the optimization problem of the monopolist retail chain: We find the optimal solution in each case by solving the first order conditions simultaneously. If the optimal solution is not in the interior of the feasible region, we calculate the optimal solutions over the end-points of $a$ and $b$ that can be achieved in the feasible region, keeping the optimal end-point solution that yields the maximum profit. We repeat this procedure and obtain the optimal locations and profit, if any, in each case. We then compare these profits across all cases and select the point that maximizes the profit.

Algorithm 1 below finds the optimal solutions in the interior of the respective feasible regions across all cases and compares these solutions, in order to compute the optimal total profit and locations. Algorithm 2 below shows the pseudo code for implementation of steps 2-4 of Algorithm 1 in case (1). See the online appendix for the pseudo codes in cases (2)-(8). Proposition 4 proves

\section{Algorithm 1 Optimal store locations for the monopolist retail} chain.

\section{1: Set $i=1$.}

2: Identify the end-points of the intervals for $a$ and $b$ in case (i).

3: Find the global optima for the unconstrained problem in case (i).

- Calculate the first order conditions of $\pi_{T}^{(i)}(a, b)$. Solve these two equations simultaneously to find the global optima $\left(a_{i}, b_{i}\right)$.

4: IF $\left(a_{i}, b_{i}\right)$ is in the interval of case (i), then $\left(a_{i}, b_{i}\right)$ is an optimal solution in case (i).

ELSE

- Find the optimal profit over the feasible region of $a$, at each end-point of the interval of $b$ that can be achieved. If an end-point for $b$ cannot be specified, no solution exists.

- Find the optimal profit over the feasible region of $b$, at each end-point of the interval of $a$ that can be achieved. If an end-point for $a$ cannot be specified, no solution exists.

- $\left(\tilde{a}_{i}, \tilde{b}_{i}\right)$ maximizing the profit across all feasible end-point solutions is an optimal solution in case $(i)$. Set $\left(a_{i}, b_{i}\right)=$ $\left(\tilde{a}_{i}, \tilde{b}_{i}\right)$.

- If there exists no $\left(\tilde{a}_{i}, \tilde{b}_{i}\right)$, then no solution exists in case (i).

5: IF $i<8$, set $i=i+1$ and go to step 2 .

ELSE let $i^{*}=\arg \max _{i \in\{1, \ldots, 8\}} \pi_{T}^{(i)}\left(a_{i}, b_{i}\right) .\left(a_{i^{*}}, b_{i^{*}}\right)$ are the optimal locations and $\pi_{T}^{\left(i^{*}\right)}\left(a_{i^{*}}, b_{i^{*}}\right)$ is the optimal total profit.

that Algorithm 1 always finds an optimal solution to the monopolist retail chain's problem.

Proposition 4. There always exists an optimal solution in the monopolist retail chain's problem and Algorithm 1 always finds the optimal solution. Algorithm 1 also minimizes the total transportation cost of the monopolist retail chain.

In Section 5 we numerically compare the monopoly market to the duopoly market, in order to investigate the impacts of competition on the location decisions, and the resulting costs and emissions. In Section 5 we employ Algorithm 1 to find the solution of the monopolist retail chain's problem.

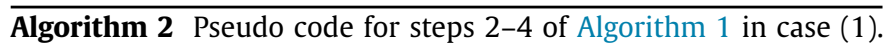

1: Identify the end-points of the intervals for $a$ and $b$ in case (1). The upper end-points are $\left(a_{1}^{U}, b_{1}^{U}\right)=$ (undefined, $m$ ) and the lower end-points are $\left(a_{1}^{L}, b_{1}^{L}\right)=(0$, undefined $)$.

2: Find the global optima for the unconstrained problem in case (1).

3: IF $\left(a_{1}, b_{1}\right)$ is in the interval of case $(1)$, then $\left(a_{1}, b_{1}\right)$ is an optimal solution in case (1).

ELSE

- Set $b_{1}=m$ and take the derivative of $\pi_{T}^{(1)}\left(a, b_{1}\right)$ to find $a_{1}$. IF $a_{1}$ is in the interval of case $(1)$, then $\left(a_{1}, b_{1}\right)$ is a feasible solution in case (1).

ELSEIF $a_{1} \geq b_{1}$, no solution exists.

ELSEIF $a_{1}<0$, set $a_{1}=0$ to find the value $\pi_{T}^{(1)}\left(a_{1}, b_{1}\right)$. END

- Set $a_{1}=0$ and take the derivative of $\pi_{T}^{(1)}\left(a_{1}, b\right)$ to find $b_{1}$. IF $b_{1}$ is in the interval of case (1), then $\left(a_{1}, b_{1}\right)$ is a feasible solution in case (1).

ELSEIF $a_{1} \geq b_{1}$, no solution exists.

ELSEIF $b_{1}>m$, set $b_{1}=m$ to find the value $\pi_{T}^{(1)}\left(a_{1}, b_{1}\right)$. END

- The end-point solution $\left(\tilde{a}_{1}, \tilde{b}_{1}\right)$ maximizing the profit is an optimal solution in case $(1)$. Set $\left(a_{1}, b_{1}\right)=\left(\tilde{a}_{1}, \tilde{b}_{1}\right)$.

END

\section{Table 6}

Parameter values used in calculation of $c_{c}$ and $c_{t}$. Units are $f_{j}=L /$ kilometer, $e_{j}=k g \mathrm{CO}_{2} / L, v_{j}=\$ /$ kilometer, $p_{j}=\$ / L, q_{j}=k g$.

\begin{tabular}{lllllll}
\hline & $f_{j}$ & $e_{j}$ & $v_{j}$ & $p_{j}$ & $q_{j}$ & $p_{e, j}$ \\
\hline Consumer $(c)$ & 0.111 & 2.325 & 0.0804 & 0.98 & 18 & $\{0,1, \ldots, 5\}$ \\
Retailer $(t)$ & 0.392 & 2.669 & 0.4840 & 1.05 & 20,000 & $\{0,1, \ldots, 5\}$ \\
\hline
\end{tabular}

\section{Numerical experiments}

In this section, we conduct a comprehensive numerical study to extend our theoretical results in the competitive market and monopoly settings. We first examine the retailers' location decisions with respect to the major parameters of our model, cf. Section 5.1. We then link these results to the total system performance measures, i.e., the total profit and emission levels, cf. Section 5.2. In order to better show the effects of competition, we plot both the competitive market and monopoly solutions in the same figures. In our analysis we also consider a central policymaker whose objective is to minimize total emissions generated subject to the fact that every consumer purchases a product, i.e., the market is fully functional. We compare the competitive market and monopoly solutions to the optimal locations and emission levels from the central policymaker's perspective.

We consider instances in which $\lambda=5, m \in\{0,0.25,0.5\}$, and $p \in\{6.5,7.5, . ., 12.5\}$. To be as realistic as possible, we base our calculation of $c_{c}$ and $c_{t}$ on the experimental setup used by Cachon (2014) and Park et al. (2015); see Table 6. ${ }^{2}$ We also vary the carbon prices $p_{e, c}$ and $p_{e, t}$ between 0 and 5 in a similar way as in Park et al. (2015); again, see Table 6. Both retailers generate positive profits in each of our instances. ${ }^{3}$ For the competitive (duopoly) market, we find the equilibrium locations based on the

\footnotetext{
2 To reflect a realistic setting and the same trade-offs as in Cachon (2014) and Park et al. (2015), we multiply $\lambda_{A}(a, b), \lambda_{B}(a, b), d_{A c}(a, b), d_{B c}(a, b), d_{A t}(a, b)$, and $d_{B t}(a, b)$ by 100 so that our location problem on the unit line is equivalent to the location problem on a 100 kilometer-long line.

3 In all our instances, serving even the most distant customer has been profitable for both retailers.
} 
intersection of the best responses. ${ }^{4}$ We observed either symmetric or asymmetric equilibrium in each of our instances. ${ }^{5}$ Without loss of generality, if there are two equilibria such that $(a, b)=(x, y)$ and $(a, b)=(y, x)$, we only present the pair with $a<b$.

\subsection{Retail locations}

Figs. 1-3 show how the equilibrium locations in the competitive market and the optimal locations in the monopoly market vary depending on the product price $(p)$, the price of carbon per unit released from consumer transportation $\left(p_{e, c}\right)$, and the price of

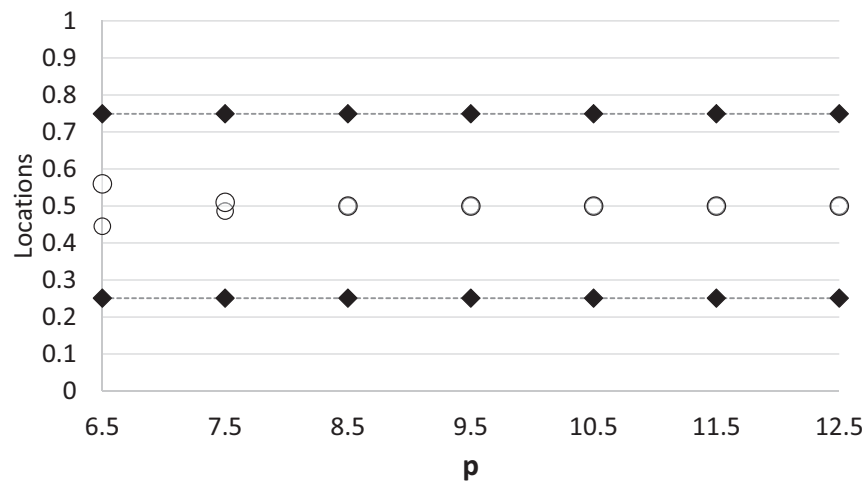

(a) $p_{e, c}=p_{e, t}=2$

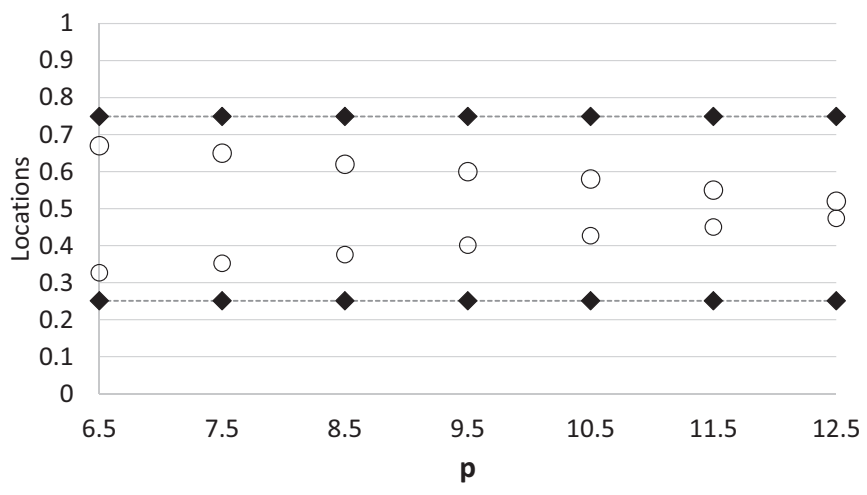

(b) $p_{e, c}=p_{e, t}=4$

Fig. 1. Locations vs. product price when $m=0.5$. Each symbol "o" indicates a location under competition, " $\$$ " a location in monopoly, and “--" minimum-emission locations.

carbon per unit released from replenishment transportation $\left(p_{e, t}\right)$, respectively. Figs. 1-3 also exhibit the locations that minimize the total carbon emissions in the market. Each of these figures contains two plots, each with different values for $p_{e, t}$ and/or $p_{e, c}$.

The location decisions under competition are driven by market incentives (demand and product price) as well as transportation costs (from both consumer travels and inventory replenishment). We observe from Fig. 1(a) that, when the product price is sufficiently high, symmetric equilibria exist in the middle of the market, i.e., both retailers choose the same location in equilibrium. In these cases, as also described in Proposition 3, the transportation costs are relatively small compared to the product price (and mar-

\footnotetext{
${ }^{4}$ We have a tolerance of 0.005 in our computations: If the difference is greater than 0.005 , then the best responses do not intersect, and no equilibrium results.

${ }^{5}$ Equilibrium may not exist in some select cases. We observe nonexistence of equilibrium when $c_{c}$ and $c_{t}$ are comparable in value (which is not likely in our problem setting) and the warehouse location favors one side of the market. Equilibrium always exists when $m=0.5$.
}

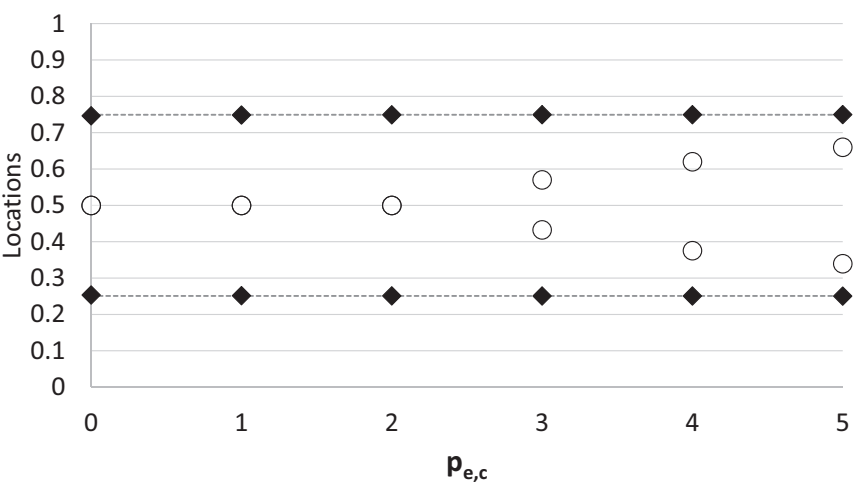

(a) $p_{e, t}=2, p=8.5$

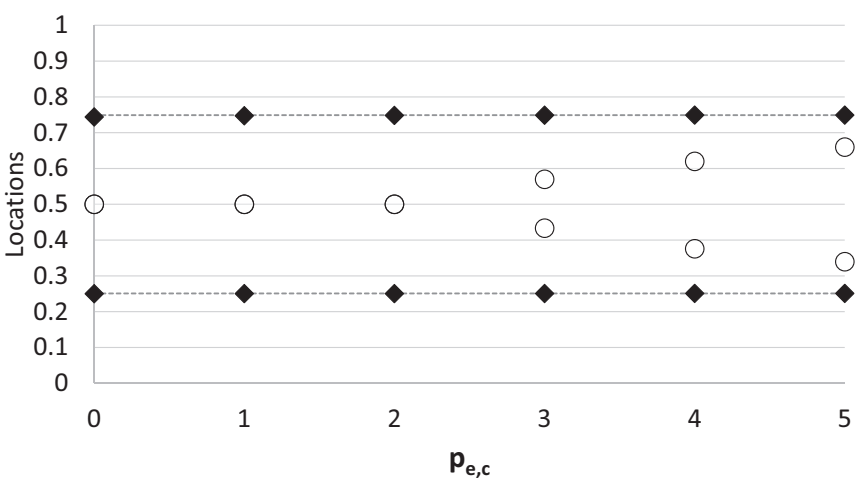

(b) $p_{e, t}=4, p=8.5$

Fig. 2. Locations vs. carbon price for consumer travels when $m=0.5$. Each symbol "॰" indicates a location under competition, " $\downarrow$ " a location in monopoly, and “--" minimum-emission locations.

gin) so that the retailers' location decisions are mainly driven by demand. Thus, given the competitor's location, each retailer wants to stay as close to her competitor as possible in order to capture a bigger market. This result is in line with the "minimal differentiation" equilibrium result in Hotelling (1929): firms compete on location to split the total market demand and choose the same location, again in the middle of the market.

Fig. 1 also indicates that as $p$ increases, the competitive market transitions from asymmetric to symmetric equilibrium locations. As the product price (and margin) dominates the transportation costs further, demand becomes the main driver of retailers' decisions, and both retailers end up in the middle of the market in equilibrium. Note that symmetric equilibrium always occurs in the middle of the market. Asymmetric equilibrium arises when the retailers move toward the middle of their respective markets due to the significant transportation costs compared to the market incentives. This is when competition is less intense and the retail locations partition the market more effectively.

The monopolist retail chain's location decisions are only driven by the transportation costs. Because serving the most distant customer is profitable in each of our instances, the monopolist retailer is guaranteed to have the revenue of the whole market. The store locations are therefore set to minimize the transportation costs, and are not affected by the product price. Thus, as illustrated in Figs. $1-3$, the store locations $(0.25,0.75)$ perfectly partition the market when the warehouse is in the middle of the market. All these observations lead to Remark 1 below.

Remark 1. As $p$ increases, the competing retailers' locations move from asymmetric to mid-market symmetric equilibrium, but the monopolist retailer's location decisions do not change. 


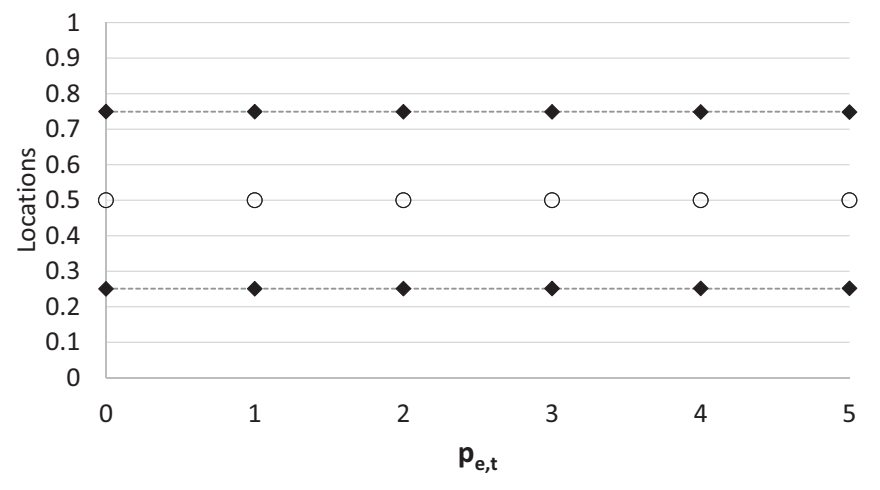

(a) $p_{e, c}=2, p=8.5$

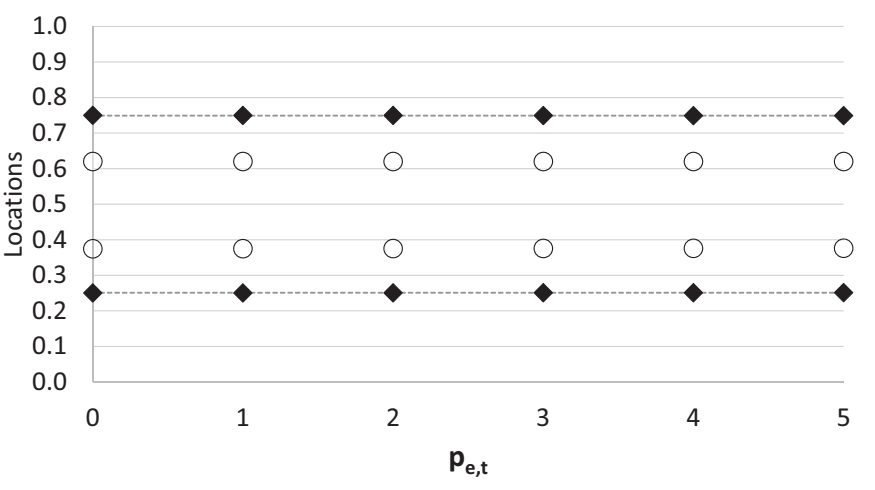

(b) $p_{e, c}=4, p=8.5$

Fig. 3. Locations vs. carbon price for inventory replenishment when $m=0.5$. Each symbol "o" indicates a location under competition, "\$" a location in monopoly, and “--" minimum-emission locations.

Figs. 2 and 3 show the effects of increased $p_{e, c}$ and $p_{e, t}$ on the location decisions. A high $p_{e, c}\left(p_{e, t}\right)$ translates into a high consumer (replenishment) transportation cost. Thus, as $p_{e, c}$ increases, the average distance of a retailer to its customers becomes so critical that the retailers approach the middle of their respective markets. Increased $p_{e, c}$ therefore creates a reverse effect to that of the market incentives and competition. As $p_{e, t}$ increases, the replenishment distance to the warehouse (a retailer's own supply chain structure) becomes critical, and thus we expect the retailers to approach the warehouse. However, under the realistic parameter values listed in Table $6, c_{c}$ is significantly greater than $c_{t}$. For instance, if $p_{e, c}=p_{e, t}=1$, then $c_{c}=248.5$ and $c_{t}=0.98$. This is mainly due to the economies of scale that the retailer enjoys in making replenishment runs with trucks, as opposed to individual customers picking up their shopping list from a retailer. As a result, as $p_{e, t}$ increases, we observe only a very slight change in location decisions in both the monopoly and competitive market settings (see Fig. 3, and Tables A.1 and A.2 in Appendix A). In the competitive market setting, $p_{e, t}$ may have an effect only if the equilibrium is already asymmetric, i.e., if the product price is low enough or the carbon price for consumer transportation is high enough. We summarize these observations in Remarks 2 and 3 below.

Remark 2. As $p_{e, c}$ increases, (i) the retail locations move towards the middle of their respective markets, (ii) the competing retailers' locations move from symmetric to asymmetric equilibrium, and (iii) the monopolist retailer's location decisions only change slightly.

Remark 3. As $p_{e, t}$ increases, the retail locations only slightly approach the warehouse in both the competitive market and
Table 7

\begin{tabular}{llll}
\multicolumn{4}{l}{ Retail locations when $p_{e, t}=5$ and $p=6.5}$. \\
\hline \multicolumn{2}{l}{ Competing retailers } \\
\hline$p_{e, c}$ & $m=0$ & $m=0.25$ & $m=0.5$ \\
\hline 0 & $(0.500,0.500)$ & $(0.500,0.500)$ & $(0.500,0.500)$ \\
1 & $(0.500,0.500)$ & $(0.500,0.500)$ & $(0.500,0.500)$ \\
2 & $(0.437,0.550)$ & $(0.438,0.550)$ & $(0.447,0.560)$ \\
3 & $(0.360,0.630)$ & $(0.366,0.630)$ & $(0.371,0.630)$ \\
4 & $(0.323,0.670)$ & $(0.324,0.670)$ & $(0.327,0.670)$ \\
5 & $(0.296,0.700)$ & $(0.297,0.700)$ & $(0.299,0.700)$ \\
Monopolist retail chain & & \\
0 & $(0.243,0.743)$ & $(0.250,0.745)$ & $(0.257,0.743)$ \\
1 & $(0.247,0.747)$ & $(0.250,0.748)$ & $(0.253,0.747)$ \\
2 & $(0.248,0.748)$ & $(0.250,0.749)$ & $(0.252,0.748)$ \\
3 & $(0.249,0.749)$ & $(0.250,0.749)$ & $(0.251,0.749)$ \\
4 & $(0.249,0.749)$ & $(0.250,0.749)$ & $(0.251,0.749)$ \\
5 & $(0.249,0.749)$ & $(0.250,0.749)$ & $(0.251,0.749)$ \\
\hline
\end{tabular}

monopoly settings, except when the equilibrium is symmetric due to low $p_{e, c}$ or high $p$ in the competitive market setting.

Table 7 summarizes the retail locations for different warehouse locations when $p_{e, t}$ is 5 , which is the highest available value in Table 6. Similar to the effect of increased $p_{e, t}$, the retail locations only slightly shift towards the warehouse under both settings. In many instances only one retail location changes with the warehouse location. And the warehouse location does not have an effect at all if the market is highly competitive (with high $p$ or low $p_{e, c}$ ) and the equilibrium is symmetric. The monopolist retail chain, however, becomes more responsive to the warehouse location as $p_{e, c}$ decreases. This is because the store location decision minimizes the sum of the two transportation costs, and thus it is more affected by the replenishment transportation cost if the consumer transportation cost is low.

Remark 4. The warehouse location only slightly affects the retail location decisions in both the competitive market and monopoly settings. It does not affect at all when $p_{e, c}$ is low (or $p$ is high) in the competitive market setting.

\subsection{Carbon emissions and carbon tax calibration}

We next compare the carbon emissions generated in the competitive market and monopoly settings. We assess the impact of the market parameters and carbon prices on the system emission performance. We also examine the profit loss under carbon tax that is enforced through increased carbon price(s).

Table 8 compares the total emission levels with two benchmark cases: (1) the total emission level in the market when all consumers are served and the carbon price enforced on consumer transportation is zero, and (2) the minimum emission level that can be achieved with two stores in the market when all consumers are served. Our comparison with (1) yields "Reduction in Emissions," while our comparison with (2) yields "Emission Overage." Table 8 also compares the total profit with that in case (1), in order to assess the negative economic implications of extra taxes on the market. Fig. 4 shows how the total emission and profit levels vary depending on the product price and the carbon price enforced on replenishment transportation. (Tables A.3-A.5 in Appendix A list the total emission and profit levels in many other instances.)

Table 8 and Fig. 4 indicate that the total emission levels in the competitive market are higher than those in the monopoly setting. In fact, the monopolist retail chain achieves the minimum or nearminimum emission levels, no matter how low the carbon prices are. When there is no competition in the market, accountability for consumer travels as well as replenishment transportation is suffi- 


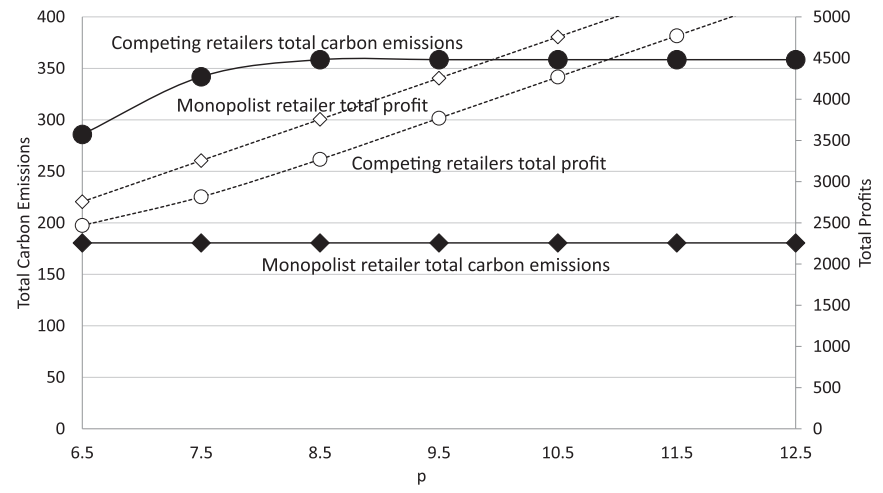

(a) Emission and profit levels vs. product price when $p_{e, t}=2$.

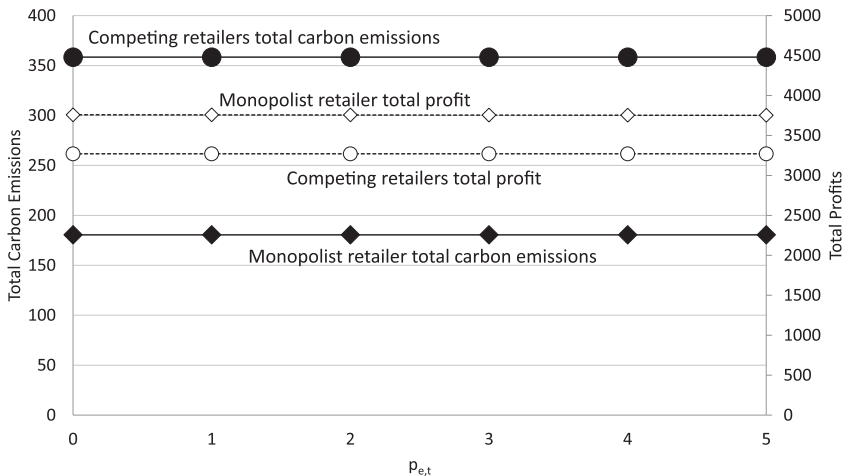

(b) Emission and profit levels vs. carbon price for inventory replenishment when $p=8.5$.

Fig. 4. Emission and profit levels when $m=0.5$ and $p_{e, c}=2$. In each instance the monopolist retailer locations yield the minimum achievable emission level.

\section{Table 8}

Emission and profit levels when $m=0.5, p=8.5$, and $p_{e, t}=2$. Reduction in emissions (profits) gives the \% reduction in the emission (profit) level when $p_{e, c}=0$. Emission overage gives the \% increase in the minimum achievable emission level when everyone in the market is served.

\begin{tabular}{|c|c|c|c|c|c|}
\hline \multicolumn{6}{|c|}{ Competing retailers } \\
\hline$p_{e, c}$ & $\begin{array}{l}\text { Total } \\
\text { emissions }\end{array}$ & $\begin{array}{l}\text { Total } \\
\text { profit }\end{array}$ & $\begin{array}{l}\text { Reduction in } \\
\text { emissions (\%) }\end{array}$ & $\begin{array}{l}\text { Reduction in } \\
\text { profits (\%) }\end{array}$ & $\begin{array}{l}\text { Emission } \\
\text { overage (\%) }\end{array}$ \\
\hline 0 & 358.44 & 3987.25 & - & - & $98.55 \%$ \\
\hline 1 & 358.44 & 3628.81 & $0.00 \%$ & $8.99 \%$ & $98.55 \%$ \\
\hline 2 & 358.44 & 3270.38 & $0.00 \%$ & $17.98 \%$ & $98.55 \%$ \\
\hline 3 & 273.87 & 3227.96 & $23.59 \%$ & $19.04 \%$ & $51.71 \%$ \\
\hline 4 & 226.58 & 3178.77 & $36.79 \%$ & $20.28 \%$ & $25.51 \%$ \\
\hline 5 & 203.14 & 3087.83 & $43.33 \%$ & $22.56 \%$ & $12.53 \%$ \\
\hline \multicolumn{6}{|c|}{ Monopolist retail chain } \\
\hline 0 & 180.54 & 4114.94 & - & - & $0.01 \%$ \\
\hline 1 & 180.53 & 3935.69 & $0.01 \%$ & $4.36 \%$ & $0.00 \%$ \\
\hline 2 & 180.52 & 3756.69 & $0.01 \%$ & $8.71 \%$ & $0.00 \%$ \\
\hline 3 & 180.52 & 3577.25 & $0.01 \%$ & $13.07 \%$ & $0.00 \%$ \\
\hline 4 & 180.52 & 3398.03 & $0.01 \%$ & $17.42 \%$ & $0.00 \%$ \\
\hline 5 & 180.52 & 3218.81 & $0.01 \%$ & $21.78 \%$ & $0.00 \%$ \\
\hline
\end{tabular}

cient to align the monopolist retailer's profit objective with minimizing the total emission level, even when the carbon tax is virtually zero. Thus increasing the carbon tax in the monopoly setting has no effect other than hurting the total profit.

When the retailers compete on locations, carbon tax is necessary in reducing total carbon emissions. As we observed in Section 5.1, the carbon tax on consumer transportation $\left(p_{e, c}\right)$ can effectively induce changes in retail locations, and thus it helps reduce the total emission levels. Table 8 shows that $p_{e, c}$ has to be high enough compared to other parameters like $p$ to be effective at all. At low values, retailers prefer to ignore this additional cost while making their decisions and only pay their due. Hence it does not affect the total emissions but hurts the overall profit. Interestingly, $p_{e, c}$ continues to be effective at the medium-to-high range: there are no diminishing returns of carbon tax on consumer transportation. ${ }^{6}$ Therefore, from the policymaker's perspective, conservative carbon prices may prove to be a bigger failure than aggressive ones. However, the minimum profit loss under those carbon prices that help reduce emissions is considerably high $(19.04 \%$ in Table 8$).^{7}$

\footnotetext{
${ }^{6}$ Setting $p_{e, c}=5$ in Table 8 brings a $43.33 \%$ reduction in emissions but also leads to a $22.56 \%$ loss in profits. This alternative is more efficient than setting $p_{e, c}=3$ or $p_{e, c}=4$.

${ }^{7}$ In our numerical experiments, the lowest carbon price for consumer travels that reduces carbon emissions leads to a $17.15 \%$ loss in profits. This minimum profit loss
}

Remark 5. When sufficiently high, $p_{e, c}$ is effective in curbing total carbon emissions, especially in competitive markets. If $p_{e, c}$ is too low, it only hurts profits but does not affect carbon emissions.

The product price determines the market profitability, and consequently the competition intensity between the two retailers. As also discussed in Section 5.1, as the market becomes more profitable, the retailers tend to ignore the carbon taxes and approach each other's location, towards the middle of the market. As a result, the total emission levels in the competitive market increase with the product price. But the emission levels remain the same when the product price rises above a certain threshold, and the retailers reach a symmetric equilibrium in the middle of the market. The monopolist retail chain, however, is not affected by the product price since it already captures the whole demand.

Remark 6. The total carbon emission levels in the competitive market tend to increase with $p$.

As observed in Section 5.1, taxing replenishment transportation through $p_{e, t}$ has virtually no effect towards reducing total emissions. It may even result in a slight increase in some cases, especially when the warehouse is closer to one end of the market and the carbon prices are not calibrated well (for example, see Table A.4). The main reason behind this result is that the carbon tax on inventory replenishment can be effectively reduced by full-truckload transportation decisions by retailers and takes much lower values than that on consumer travels. This also explains why the total profit is not affected much by $p_{e, t}$. Thus the carbon tax on the retailers' own supply chains is mainly ineffective on both the total emission and profit levels.

Remark 7. Increasing $p_{e, t}$ has no significant effect towards reducing the total emission or profit levels.

When the warehouse is closer to one end of the market as opposed to being in the middle, the total traveled distance is greater in both settings: If there is a symmetric equilibrium in the competitive market, both retailers' trucks should travel farther for each replenishment. If there is an asymmetric equilibrium in the competitive market, or in the monopoly setting, the locations tend to move towards the warehouse in order to balance the consumer-related and replenishment-related costs. This increases consumer-related transportation at the cost of a restrained rise in replenishment transportation. Consequently the total emission levels increase in both settings. Similar to the effect of increased

occurs when the product price is lowest, i.e., $p=6.5$, and the profit loss increases with the product price. 
$p_{e, t}$, the warehouse location only has a slight effect, as a result of the economies of scale in replenishment transportation. (Table A.5 provides evidence on the effect of the warehouse location on the minimum emission levels that can be achieved, as well as the emission levels in both settings.)

Remark 8. As the warehouse favors one side of the market, the total emission levels tend to increase but not significantly.

The control of the total carbon emissions in a market is critical from an environmental perspective. A policymaker who wants to minimize the carbon emissions generated can easily manage monopoly markets. Enforcing very low carbon prices provides sufficient incentives for the monopolist to choose the store locations that minimize the transportation-related emissions. Competitive markets, however, are more complicated. As the product profitability increases, the retailers become more inclined to ignore emission-related negative externalities and to go after the market. Thus the carbon tax values should be calibrated to the profitability and competition intensity of the market. More often than not, the carbon tax on the retailers' own supply chains does not affect the retailers' location decisions and total emissions in the market. However, the retailers are responsive to the carbon tax on consumer travels when the tax values are sufficiently high. A low carbon tax does not reduce the total emissions at all but only drains the total profits. Based on these observations, we recommend a tax policy contingent on the profile of customers served to be enforced on the retailers. Last, our numerical experiments reveal that a uniform carbon price across transportation types and markets is the least effective and sometimes harmful to the businesses.

\section{Concluding remarks}

We have studied the simultaneous location problem of two retailers under carbon tax in the monopoly and duopoly settings. Location decisions are influenced by transportation costs including carbon taxes of both replenishment trucks and consumer vehicles. We also allow for heterogeneous carbon prices enforced in the market, i.e., emission-related charges on replenishment trucks may differ from its counterparts on consumer vehicles. We first establish the equilibrium locations in a special case of the duopoly setting, and the optimal solution algorithm for the location problem in the monopoly setting. We then evaluate the system emission and profit levels under different carbon tax levels.

Our analysis shows that competitive markets tend to build up emission levels, because retailers' decisions are dominated by market forces instead of emission-related charges. Competing retailers respond to carbon tax only when it is high enough. Monopolist chains, however, can achieve the minimum emission level possible at moderate carbon prices. We therefore conclude that reducing emissions is possible and comes at a cost, especially in competitive markets.

Taxing consumer transportation is more effective in reducing system emissions than taxing transportation in supply chains. The main reason behind this is the economies of scale a retailer leverages in managing her own operations, which renders both the cost and emission load of replenishment transportation insignificant compared to those of consumer transportation. Thus retailers are more responsive to carbon tax on consumer vehicles, and when they are responsive it also makes a difference for system emissions. Carbon tax on retail supply chains, however, is in general not effective and only drains system profits. Also note that taxing replenishment transportation may induce retail locations to approach arbitrary warehouse locations and thus may not produce robust results across different markets.

We thus recommend that the central policymaker implement a flexible regulation scheme with varying carbon prices across transportation types and markets. Such flexibility may be very useful in achieving the targeted emission reduction and restraining the profit erosion. Defining firm liabilities on emissions in relation with own operations only (scope 1) may fail to be effective or helpful in many cases; consumer patronage of a retailer (scope 3) may be the dominant source of emissions in the whole system.

In this study we focus on the effects of competition and regulatory forces on retail location decisions. To concentrate on the location decisions free of the interaction with other factors, we assume that the two competing retailers face deterministic demand, sell perfectly substitutable products at an exogenous market price, at standard stores of sufficient size. Our research can be extended to allow for random demand and positive storage costs. Intuitively, we would expect the role of the storage costs to be similar to that of the transportation cost for replenishment. This is because the storage costs would enforce the retailers to shorten their replenishment distances (and thus lead-times) to hold less inventory. A retailer need not keep inventory if it is at the same location as the supplier and the replenishment leadtime is zero. Future extensions of our research could also allow consumers to be non-uniformly distributed over the unit line. Another direction for future research is to extend our model to include the joint replenishment problem. Retailers might prefer to procure the items from the supplier via a common truck in order to share transportation costs.

Appendix A. Additional numerical results

Table A1

Retail locations when $p=8.5$ and $m=0.5$.

\begin{tabular}{lllllll}
\hline \multirow{2}{*}{$p_{e, c}$} & $p_{e, t}$ & \multicolumn{5}{l}{} \\
\cline { 2 - 7 } & 0 & 1 & 2 & 3 & 4 & 5 \\
\hline \multicolumn{2}{c}{ Competing retailers } & & & & \\
0 & $(0.500,0.500)$ & $(0.500,0.500)$ & $(0.500,0.500)$ & $(0.500,0.500)$ & $(0.500,0.500)$ & $(0.500,0.500)$ \\
1 & $(0.500,0.500)$ & $(0.500,0.500)$ & $(0.500,0.500)$ & $(0.500,0.500)$ & $(0.500,0.500)$ & $(0.500,0.500)$ \\
2 & $(0.500,0.500)$ & $(0.500,0.500)$ & $(0.500,0.500)$ & $(0.500,0.500)$ & $(0.500,0.500)$ & $(0.500,0.500)$ \\
3 & $(0.432,0.570)$ & $(0.432,0.570)$ & $(0.433,0.570)$ & $(0.433,0.570)$ & $(0.433,0.570)$ & $(0.434,0.570)$ \\
4 & $(0.375,0.620)$ & $(0.375,0.620)$ & $(0.375,0.620)$ & $(0.376,0.620)$ & $(0.376,0.620)$ & $(0.376,0.620)$ \\
5 & $(0.339,0.660)$ & $(0.339,0.660)$ & $(0.339,0.660)$ & $(0.340,0.660)$ & $(0.340,0.660)$ & $(0.340,0.660)$ \\
Monopolist retail chain & & & & & \\
0 & $(0.251,0.749)$ & $(0.252,0.748)$ & $(0.254,0.746)$ & $(0.255,0.745)$ & $(0.256,0.744)$ & $(0.257,0.743)$ \\
1 & $(0.250,0.750)$ & $(0.251,0.749)$ & $(0.251,0.749)$ & $(0.252,0.748)$ & $(0.253,0.747)$ & $(0.253,0.747)$ \\
2 & $(0.250,0.750)$ & $(0.251,0.749)$ & $(0.251,0.749)$ & $(0.251,0.749)$ & $(0.252,0.748)$ & $(0.252,0.748)$ \\
3 & $(0.250,0.750)$ & $(0.250,0.750)$ & $(0.251,0.749)$ & $(0.251,0.749)$ & $(0.251,0.749)$ & $(0.251,0.749)$ \\
4 & $(0.250,0.750)$ & $(0.250,0.750)$ & $(0.251,0.749)$ & $(0.251,0.749)$ & $(0.251,0.749)$ & $(0.251,0.749)$ \\
5 & $(0.250,0.750)$ & $(0.250,0.750)$ & $(0.250,0.750)$ & $(0.251,0.749)$ & $(0.251,0.749)$ & $(0.251,0.749)$ \\
\hline
\end{tabular}


Table A2

Retail locations when $p=6.5$ and $m=0$.

\begin{tabular}{|c|c|c|c|c|c|c|}
\hline \multirow[t]{2}{*}{$p_{e, c}$} & \multicolumn{6}{|l|}{$p_{e, t}$} \\
\hline & 0 & 1 & 2 & 3 & 4 & 5 \\
\hline \multicolumn{7}{|c|}{ Competing retailers } \\
\hline 0 & $(0.500,0.500)$ & $(0.500,0.500)$ & $(0.500,0.500)$ & $(0.500,0.500)$ & $(0.500,0.500)$ & $(0.500,0.500)$ \\
\hline 1 & $(0.500,0.500)$ & $(0.500,0.500)$ & $(0.500,0.500)$ & $(0.500,0.500)$ & $(0.500,0.500)$ & $(0.500,0.500)$ \\
\hline 2 & $(0.443,0.560)$ & $(0.442,0.650)$ & $(0.442,0.560)$ & $(0.441,0.560)$ & $(0.440,0.560)$ & $(0.437,0.550)$ \\
\hline 3 & $(0.368,0.630)$ & $(0.368,0.630)$ & $(0.367,0.630)$ & $(0.367,0.630)$ & $(0.366,0.630)$ & $(0.366,0.630)$ \\
\hline 4 & $(0.325,0.670)$ & $(0.325,0.670)$ & $(0.324,0.670)$ & $(0.324,0.670)$ & $(0.324,0.670)$ & $(0.323,0.670)$ \\
\hline 5 & $(0.298,0.700)$ & $(0.298,0.700)$ & $(0.297,0.700)$ & $(0.297,0.700)$ & $(0.297,0.700)$ & $(0.296,0.700)$ \\
\hline \multicolumn{7}{|c|}{ Monopolist retail Chain } \\
\hline 0 & $(0.249,0.749)$ & $(0.248,0.748)$ & $(0.246,0.746)$ & $(0.245,0.745)$ & $(0.244,0.744)$ & $(0.243,0743)$ \\
\hline 1 & $(0.250,0.750)$ & $(0.249,0.749)$ & $(0.249,0.748)$ & $(0.248,0.748)$ & $(0.247,0.747)$ & $(0.247,0.747)$ \\
\hline 2 & $(0.250,0.750)$ & $(0.249,0.749)$ & $(0.249,0.749)$ & $(0.249,0.749)$ & $(0.248,0.748)$ & $(0.248,0.748)$ \\
\hline 3 & $(0.250,0.750)$ & $(0.250,0.750)$ & $(0.249,0.749)$ & $(0.249,0.749)$ & $(0.249,0.749)$ & $(0.249,0.749)$ \\
\hline 4 & $(0.250,0.750)$ & $(0.250,0.750)$ & $(0.249,0.749)$ & $(0.249,0.749)$ & $(0.249,0.749)$ & $(0.249,0.749)$ \\
\hline 5 & $(0.250,0.750)$ & $(0.250,0.750)$ & $(0.250,0.750)$ & $(0.249,0.749)$ & $(0.249,0.749)$ & $(0.249,0.749)$ \\
\hline
\end{tabular}

Table A3

Emission and profit levels when $m=0.5$. Reduction in emissions (profits) gives the \% reduction in the emission (profit) level when $p_{e, c}=0$. Emission overage gives the \% increase in the minimum achievable emission level when everyone in the market is served.

\begin{tabular}{|c|c|c|c|c|c|c|}
\hline$p_{e, t}$ & $p_{e, c}$ & $\begin{array}{l}\text { Total } \\
\text { emissions }\end{array}$ & $\begin{array}{l}\text { Total } \\
\text { profit }\end{array}$ & $\begin{array}{l}\text { Reduction in } \\
\text { emissions (\%) }\end{array}$ & $\begin{array}{l}\text { Reduction in } \\
\text { profits (\%) }\end{array}$ & $\begin{array}{l}\text { Emission } \\
\text { overage (\%) }\end{array}$ \\
\hline \multicolumn{7}{|c|}{ Competing retailers, $p=6.5$} \\
\hline 2 & 0 & 358.44 & 2987.25 & - & - & $98.55 \%$ \\
\hline 2 & 1 & 358.44 & 2628.81 & $0.00 \%$ & $12.00 \%$ & $98.55 \%$ \\
\hline 2 & 2 & 285.90 & 2468.59 & $20.24 \%$ & $17.36 \%$ & $58.37 \%$ \\
\hline 2 & 3 & 221.14 & 2425.07 & $38.30 \%$ & $18.82 \%$ & $22.50 \%$ \\
\hline 2 & 4 & 197.63 & 2316.28 & $44.86 \%$ & $22.46 \%$ & $9.48 \%$ \\
\hline 2 & 5 & 187.26 & 2179.47 & $47.76 \%$ & $27.04 \%$ & $3.73 \%$ \\
\hline 4 & 0 & 358.44 & 2987.25 & - & - & $98.55 \%$ \\
\hline 4 & 1 & 358.44 & 2628.81 & $0.00 \%$ & $12.00 \%$ & $98.55 \%$ \\
\hline 4 & 2 & 286.47 & 2466.44 & $20.08 \%$ & $17.43 \%$ & $58.69 \%$ \\
\hline 4 & 3 & 221.38 & 2422.83 & $38.24 \%$ & $18.89 \%$ & $22.63 \%$ \\
\hline 4 & 4 & 197.75 & 2313.95 & $44.83 \%$ & $22.54 \%$ & $9.54 \%$ \\
\hline 4 & 5 & 187.31 & 2177.04 & $47.74 \%$ & $27.12 \%$ & $3.76 \%$ \\
\hline \multicolumn{7}{|c|}{ Competing retailers, $p=8.5$. } \\
\hline 2 & 0 & 358.44 & 3987.25 & - & - & $98.55 \%$ \\
\hline 2 & 1 & 358.44 & 3628.81 & $0.00 \%$ & $8.99 \%$ & $98.55 \%$ \\
\hline 2 & 2 & 358.44 & 3270.38 & $0.00 \%$ & $17.98 \%$ & $98.55 \%$ \\
\hline 2 & 3 & 273.87 & 3227.96 & $23.59 \%$ & $19.04 \%$ & $51.71 \%$ \\
\hline 2 & 4 & 226.58 & 3178.77 & $36.79 \%$ & $20.28 \%$ & $25.51 \%$ \\
\hline 2 & 5 & 203.14 & 3087.83 & $43.33 \%$ & $22.56 \%$ & $12.53 \%$ \\
\hline 4 & 0 & 358.44 & 3987.25 & - & - & $98.55 \%$ \\
\hline 4 & 1 & 358.44 & 3628.81 & $0.00 \%$ & $8.99 \%$ & $98.55 \%$ \\
\hline 4 & 2 & 358.44 & 3270.38 & $0.00 \%$ & $17.98 \%$ & $98.55 \%$ \\
\hline 4 & 3 & 274.25 & 3225.81 & $23.49 \%$ & $19.10 \%$ & $51.92 \%$ \\
\hline 4 & 4 & 226.78 & 3176.57 & $36.73 \%$ & $20.33 \%$ & $25.62 \%$ \\
\hline 4 & 5 & 203.25 & 3085.52 & $43.30 \%$ & $22.62 \%$ & $12.59 \%$ \\
\hline \multicolumn{7}{|c|}{ Competing retailers, $p=10.5$} \\
\hline 2 & 0 & 358.44 & 4987.25 & - & - & $98.55 \%$ \\
\hline 2 & 1 & 358.44 & 4628.81 & $0.00 \%$ & $7.19 \%$ & $98.55 \%$ \\
\hline 2 & 2 & 358.44 & 4270.38 & $0.00 \%$ & $14.37 \%$ & $98.55 \%$ \\
\hline 2 & 3 & 353.81 & 3929.23 & $1.29 \%$ & $21.21 \%$ & $95.99 \%$ \\
\hline 2 & 4 & 265.60 & 3993.68 & $25.90 \%$ & $19.92 \%$ & $47.12 \%$ \\
\hline 2 & 5 & 228.35 & 3942.66 & $36.29 \%$ & $20.95 \%$ & $26.49 \%$ \\
\hline 4 & 0 & 358.44 & 4987.25 & - & - & $98.55 \%$ \\
\hline 4 & 1 & 358.44 & 4628.81 & $0.00 \%$ & $7.19 \%$ & $98.55 \%$ \\
\hline 4 & 2 & 358.44 & 4270.38 & $0.00 \%$ & $14.37 \%$ & $98.55 \%$ \\
\hline 4 & 3 & 348.77 & 3947.97 & $2.70 \%$ & $20.84 \%$ & $93.20 \%$ \\
\hline 4 & 4 & 265.88 & 3991.51 & $25.82 \%$ & $19.97 \%$ & $93.20 \%$ \\
\hline 4 & 5 & 228.52 & 3940.44 & $36.25 \%$ & $20.99 \%$ & $26.59 \%$ \\
\hline \multicolumn{7}{|c|}{ Monopolist retail chain, $p=8.5$} \\
\hline 2 & 0 & 180.54 & 4114.94 & - & - & $0.01 \%$ \\
\hline 2 & 1 & 180.53 & 3935.69 & $0.01 \%$ & $4.36 \%$ & $0.00 \%$ \\
\hline 2 & 2 & 180.52 & 3756.69 & $0.01 \%$ & $8.71 \%$ & $0.00 \%$ \\
\hline 2 & 3 & 180.52 & 3577.25 & $0.01 \%$ & $13.07 \%$ & $0.00 \%$ \\
\hline 2 & 4 & 180.52 & 3398.03 & $0.01 \%$ & $17.42 \%$ & $0.00 \%$ \\
\hline 2 & 5 & 180.52 & 3218.81 & $0.01 \%$ & $21.78 \%$ & $0.00 \%$ \\
\hline 4 & 0 & 180.60 & 4112.35 & - & - & $0.04 \%$ \\
\hline 4 & 1 & 180.53 & 3933.09 & $0.04 \%$ & $4.36 \%$ & $0.00 \%$ \\
\hline 4 & 2 & 180.52 & 3753.86 & $0.04 \%$ & $8.72 \%$ & $0.00 \%$ \\
\hline 4 & 3 & 180.52 & 3574.63 & $0.04 \%$ & $13.08 \%$ & $0.00 \%$ \\
\hline 4 & 4 & 180.52 & 3395.41 & $0.04 \%$ & $17.43 \%$ & $0.00 \%$ \\
\hline 4 & 5 & 180.52 & 3216.19 & $0.04 \%$ & $21.79 \%$ & $0.00 \%$ \\
\hline
\end{tabular}


Table A4

Emission levels when $p=8.5$.

\begin{tabular}{|c|c|c|c|c|c|c|c|}
\hline \multirow[t]{2}{*}{$p_{e, c}$} & \multirow[t]{2}{*}{$m$} & \multicolumn{6}{|l|}{$p_{e, t}$} \\
\hline & & 0 & 1 & 2 & 3 & 4 & 5 \\
\hline \multicolumn{8}{|c|}{ Competing retailers } \\
\hline 0 & 0 & 361.05 & 361.05 & 361.05 & 361.05 & 361.05 & 361.05 \\
\hline 0 & 0.25 & 359.75 & 359.75 & 359.75 & 359.75 & 359.75 & 359.75 \\
\hline 0 & 0.5 & 358.44 & 358.44 & 358.44 & 358.44 & 358.44 & 358.44 \\
\hline 2 & 0 & 361.05 & 361.05 & 361.05 & 361.05 & 361.05 & 361.05 \\
\hline 2 & 0.25 & 359.75 & 359.75 & 359.75 & 359.75 & 359.75 & 359.75 \\
\hline 2 & 0.5 & 358.44 & 358.44 & 358.44 & 358.44 & 358.44 & 358.44 \\
\hline 4 & 0 & 225.30 & 225.14 & 224.99 & 227.69 & 227.53 & 227.38 \\
\hline 4 & 0.25 & 224.01 & 223.89 & 226.61 & 226.48 & 226.36 & 226.24 \\
\hline 4 & 0.5 & 223.54 & 226.58 & 226.58 & 226.68 & 226.78 & 226.88 \\
\hline \multicolumn{8}{|c|}{ Monopolist retail chain } \\
\hline 0 & 0 & 181.83 & 181.84 & 181.84 & 181.85 & 181.87 & 181.89 \\
\hline 0 & 0.25 & 180.53 & 180.53 & 180.53 & 180.53 & 180.54 & 180.55 \\
\hline 0 & 0.5 & 180.52 & 180.53 & 180.54 & 180.54 & 180.57 & 180.64 \\
\hline 2 & 0 & 181.83 & 181.83 & 181.83 & 181.83 & 181.83 & 181.83 \\
\hline 2 & 0.25 & 180.53 & 180.53 & 180.53 & 180.53 & 180.53 & 180.53 \\
\hline 2 & 0.5 & 180.53 & 180.52 & 180.52 & 180.52 & 180.53 & 180.53 \\
\hline 4 & 0 & 181.83 & 181.83 & 181.83 & 181.83 & 181.83 & 181.83 \\
\hline 4 & 0.25 & 180.53 & 180.53 & 180.53 & 180.53 & 180.53 & 180.53 \\
\hline 4 & 0.5 & 180.53 & 180.53 & 180.52 & 180.52 & 180.52 & 180.52 \\
\hline
\end{tabular}

Table A5

Emission and profit levels when $p=6.5$ and $p_{e, t}=5$.

\begin{tabular}{llll}
\hline$p_{e, c}$ & $m=0$ & $m=0.25$ & $m=0.5$ \\
\hline \multicolumn{1}{l}{ Competing retailers } & & \\
0 & $(361.05,2971.93)$ & $(359.75,2979.59)$ & $(358.44,2987.25)$ \\
1 & $(361.05,2613.50)$ & $(359.75,2621.15)$ & $(358.44,2628.81)$ \\
2 & $(289.40,2450.99)$ & $(288.52,2457.47)$ & $(286.75,2465.37)$ \\
3 & $(221.68,2416.91)$ & $(220.57,2423.85)$ & $(221.49,2421.72)$ \\
4 & $(198.66,2306.79)$ & $(197.45,2313.99)$ & $(197.80,2312.79)$ \\
5 & $(188.47,2169.16)$ & $(187.22,2167.53)$ & $(187.34,2175.83)$ \\
Monopolist retail chain & & \\
0 & $(181.89,3103.36)$ & $(180.55,3110.99)$ & $(180.64,3111.08)$ \\
1 & $(181.84,2924.11)$ & $(180.53,2931.76)$ & $(180.54,2931.79)$ \\
2 & $(181.83,2744.89)$ & $(180.53,2752.53)$ & $(180.53,2742.56)$ \\
3 & $(181.83,2565.66)$ & $(180.53,2573.31)$ & $(180.52,2573.33)$ \\
4 & $(181.83,2386.44)$ & $(180.53,2394.09)$ & $(180.52,2394.11)$ \\
5 & $(181.83,2207.22)$ & $(180.53,2214.88)$ & $(180.52,2214.89)$ \\
Minimum & $m=0$ & $m=0.25$ & $m=0.5$ \\
emission levels & 181.83 & 180.53 & 180.52 \\
\hline
\end{tabular}

\section{Supplementary material}

Supplementary material associated with this article can be found, in the online version, at 10.1016/j.ejor.2017.10.060.

\section{References}

Aboolian, R., Berman, O., \& Krass, D. (2007). Competitive facility location model with concave demand. European Journal of Operational Research, 181(2), 598-619.

Balvers, R., \& Szerb, L. (1996). Location in the hotelling duopoly model with demand uncertainty. European Economic Review, 40(7), 1453-1461.

Benjaafar, S., Li, Y., \& Daskin, M. (2013). Carbon footprint and the management of supply chains: insights from simple models. IEEE Transactions on Automation Science and Engineering, 10(1), 99-115.

Buechel, B., \& Roehl, N. (2015). Robust equilibria in location games. European Journal of Operational Research, 240(2), 505-517.

Cachon, G. P. (2014). Retail store density and the cost of greenhouse gas emissions. Management Science, 60(8), 1907-1925.

Caro, F., Corbett, C. J., Tan, T., \& Zuidwijk, R. (2013). Double counting in supply chain carbon footprinting. Manufacturing \& Service Operations Management, 15(4), 545-558.

Dasci, A., \& Laporte, G. (2005). A continuous model for multistore competitive location. Operations Research, 53(2), 263-280.

Dasgupta, P., \& Maskin, E. (1986). The existence of equilibrium in discontinuous economic games, I: Theory. Review of Economic Studies, 53.

D’Aspremont, C., Gabszewicz, J. J., \& Thisse, J. F. (1979). On hotelling's "stability in competition”. Econometrica: Journal of the Econometric Society, 47(5), 1145-1150.
De Palma, A., Ginsburgh, V., \& Thisse, J. F. (1987). On existence of location equilibria in the 3-firm hotelling problem. The Journal of Industrial Economics, 36(2), $245-252$.

Diaz-Banez, J. M., Heredia, M., Pelegrin, B., Perez-Lantero, P., \& Ventura, I. (2011). Finding all purese strategy nash equilibria in a planar location game. European Journal of Operational Research, 214(1), 91-98.

Dobson, G., \& Karmarkar, U. S. (1987). Competitive location on a network. Operations Research, 35(4), 565-574.

Eaton, B. C., \& Lipsey, R. G. (1975). The principle of minimum differentiation considered: some new developments in the theory of spatial competition. Review of Economic Studies, 42.

Economides, N. (1986). Minimal and maimal product differentiation in hotelling's duopoly. Economics Letters, 21.

Eiselt, H. A., Laporte, G., \& Thisse, J. F. (1993). Competitive location models: a framework and bibliography. Transportation Science, 27(1), 44-54.

Eiselt, H. A., \& Sandblom, C. L. (2004). Decision analysis, location models, and scheduling problems. Springer-Verlag, Berlin Heidelberg.

Fernandez, J., Salhi, S., \& Boglarka, G. (2014). Location equilibria for a continuous competitive facility location problem under delivered pricing. Computers and Operations Research, 41, 185-195.

Godinho, P., \& Dias, J. (2010). A two-player competitive discrete location model with simultaneous decisions. European Journal of Operational Research, 207(3), 1419-1432.

Godinho, P., \& Dias, J. (2013). Two-player simultaneous location game: preferential rights and overbidding. European Journal of Operational Research, 229(3), 663-672.

Graitson, D. (1982). Spatial competition a la hotelling: a selective survey. The Journal of Industrial Economics, 31(1), 13-25.

Granot, D., Granot, F., \& Raviv, T. (2010). On competitive sequential location in a network with a decreasing demand intensity. European Journal of Operational Research, 205(2), 301-312.

Hakimi, S. L. (1983). On locating new facilities in a competitive environment. European Journal of Operational Research, 12(1), 29-35.

Hoen, K. M. R., Tan, T., Fransoo, J. C., \& van Houtum, G. J. (2014). Effect of carbon emission regulations on tranport mode selection under stochastic demand. Flexible Services and Manufacturing Journal, 26, 170-195.

Hotelling, H. (1929). Stability in competition. The Economic Journal, 39(153), 4157.

Islegen, O., Plambeck, E., \& Taylor, T. (2016). Variability in emissions cost: implications for facility location, production and shipping. In A. Atasu (Ed.), Environmentally Responsible Supply Chains. Switzerland: Springer.

Krass, D., Nedorezov, T., \& Ovchinnikov, A. (2013). Environmental taxes and the choice of green technology. Production and Operations Management, 22(5), 1035-1055.

Küçükaydın, H., Aras, N., \& Altınel, I. K. (2011). Competitive facility location problem with attractiveness adjustment of the follower. European Journal of Operational Research, 208(3), 206-220.

Meng, Q., Huang, Y., \& Cheu, R. L. (2009). Competitive facility location on decentralized supply chains. European Journal of Operational Research, 196(2), 487499.

Neven, D. (1985). Two stage (perfect) equilibrium in hotelling's model. The Journal of Industrial Economics, 33(3), 317-325.

Park, S. J., Cachon, G. P., Lai, G., \& Seshadri, S. (2015). Supply chain design and carbon penalty: monopoly vs. monopolistic competition. Production and Operations Management, 24(9), 1494-1508.

Plastria, F. (2001). Static competitive facility location: an overview of optimisation approaches. European Journal of Operational Research, 129(3), 461-470.

ReVelle, C. S., \& Eiselt, H. A. (2005). Location analysis: a synthesis and survey. European Journal of Operational Research, 165(1), 1-19.

Rhim, H., Ho, T. H., \& Karmarkar, U. S. (2003). Competitive location, production and market selection. European Journal of Operational Research, 149(1), 211-228.

Saiz, M. E., Hendrix, E. M., \& Pelegrin, B. (2011). On Nash equilibria of a competitive location-design problem. European Journal of Operational Research, 210(3), $588-593$.

Staff (2014a). British Columbia's carbon tax - the evidence mounts. The Economist. (http://www.economist.com) (Retrieved: August 25, 2016).

Staff (2014b). Climate change 2014 synthesis report. Intergovernmental Panel on Climate Change (http://www.ipcc.ch) (Retrieved: December 9, 2015).

Staff (2015). Causes of climate change. U.S. Environmental Protection Agency. (http: //www.epa.gov) (Retrieved: Decemeber 9, 2015).

Staff (2016a). Fast Facts: U.S. transportation sector greenhouse gas emissions 1990 2014. U.S. Environmental Protection Agency. (http://www.epa.gov) (Retrieved: August 25, 2016)

Staff (2016b). Greenhouse gas emissions statistics. Eurostat. (http://www.ec.europa.eu/ eurostat) (Retrieved: August 25, 2016).

Staff (2016c). What is a carbon tax?. British Columbia: Ministry of Finance. (http: //www.fin.gov.bc.ca) (Retrieved: August 25, 2016).

Staff (2017). Greenhouse gas emissions statistics. Eurostat. (http://www.ec.europa.eu/ clima/policies/transport_en) (Retrieved: July 25, 2017).

Sunar, N., \& Plambeck, E. (2016). Allocating emissions among co-products: implications for procurement and climate policy. Manufacturing $\mathcal{E}$ Service Operations Management, 18(3), 414-428.

Toffel, M. W., \& Sice, S. V. (2011). Carbon footprints: methods and calculations. Case \#9-611-075. Harvard Business School, Boston, MA. 